\title{
Criterios para la evaluación de las políticas de medio ambiente: una referencia para la evaluabilidad del cumplimiento del Protocolo de Kyoto
}

Victoriano Sierra Ludwig*

Palabras clave: Politicas públicas, protección medioambiental, Protocolo de Kyoto, desarrollo sostenible, evaluación medioambiental.

\section{El contexto específico del Protocolo de Kyoto}

\subsection{Introducción}

La «Convención Marco de las Naciones Unidas sobre Cambio Climático», aprobada al comienzo de la década de los años noventa, se fijó como objetivo: lograr la estabilización de las concentraciones de los gases de efecto invernadero en la atmósfera con la intención de frenar las aportaciones antropogénicas y de impedir sus consecuencias en el sistema climático. La «Conferencia de las Partes» asumió el reto de restablecer para el año 2.000 -individual o conjuntamente- los valores de 1990 en cuanto a las emisiones, tanto de $\mathrm{CO}_{2}$ como del conjunto de los gases con incidencia en el efecto invernadero no afectados por el Protocolo de Montreal. Estas y otras determinaciones provocaron la firma, primero, y la adopción, después, del Protocolo de Kyoto. Como es sabido, posteriormente, el Consejo de la Comunidad Europea aprobaba el Protocolo de Kyoto y asumía la obligación de cumplir todos los compromisos contraídos con arreglo al mismo. Por tanto, al decidir de forma conjunta el sometimiento a los acuerdos, la Comunidad y los Estados miembros de la UE se han erigido en co-responsables de que la Comunidad responda ante los compromisos cuantificados de reducción de emisiones. Asimismo, conforme se especifica en el artículo 3 del Protocolo de Kyoto, el objetivo en el período comprendido entre el año 2008 y el 2012, se centra en una reducción total de las emisiones no inferior al 5 \% de las de 1990 (Sierra Ludwig 2004: 45-59). Estas emisiones, expresadas en dióxido de carbono equivalente se refieren a la con-

* Grupo de Expertos Comunitarios de Economía y Medio Ambiente, ENVECO. 
tabilización agregada de los siguientes gases inductores del «efecto invernadero»: dióxido de carbono, metano, óxido nitroso, hidrofluorocarbonos, perfluorocarbonos y hexacloruro de azufre.

La reducción para el conjunto de la Comunidad Europea se ha fijado en un 8\%; correspondiendo los principales esfuerzos de reducción a Luxemburgo, Alemania y Dinamarca y, en menor medida, a Austria, Reino Unido y Holanda. Los incrementos autorizados -en función de los niveles comparativos per cápita- colocan en cabeza a Portugal y Grecia con el 27 y el 25\%, respectivamente, seguidos de España con el 15\% y con menores cotas relativas a los países restantes.

Al término de la década de los noventa, en la Unión Europea se comprobaba que la mayoría de los Estados miembros han carecido de rigor en cuestiones formales, como la mera presentación de información en cumplimiento del mecanismo de seguimiento establecido hasta el extremo de persistir las incoherencias detectadas con anterioridad en cuanto a la información sobre políticas y medidas adoptadas. Se han observado claras discrepancias, tanto por sobreestimaciones de previsiones como por subvaloraciones de los niveles alcanzables. Estas irregulares informaciones han ido en paralelo con la falta de datos sobre cada uno de los gases de efecto invernadero sometibles a control, por lo que las previsiones carecen de una base homogeneizada para proceder a comparaciones fiables. Pese a que las tendencias han sido divergentes, según el tipo de gases considerados, las emisiones totales en la Comunidad Europea se redujeron apenas en un 3,5\% entre 1900 y 2000, lo cual significa no haber alcanzado la mitad del objetivo para el período 2008-2012. Al observar las tendencias, la situación es diferente en función del tipo de emisiones. Así, mientras se han registrado descensos en metano y óxido nitroso, los gases fluorados y el dióxido de carbono -el más importante por su incidencia en el efecto invernadero- han exhibido una tónica alcista. Conviene recordar que en el año 2000 el CO 2 representaba el 82\% de las emisiones totales en la UE de este tipo de gases. En este sentido, ha sido significativa la incidencia de la reducción procedente de combustibles fósiles -que representan el $77 \%$ de las emisiones de gases de efecto invernadero en la UE- al generar una compensación de la escalada debida al transporte. El Gráfico 1, p. 45, refleja la distribución sectorial para el conjunto de los gases de efecto invernadero en la Unión Europea, correspondiente al año 2000. Asimismo, las repercusiones de la Política Agraria Común han sido determinantes en las caídas de metano y de óxido nitroso; si bien, han obedecido a efectos indirectos por la aplicación de estrategias y políticas elaboradas al margen de las consideraciones ambientales (Agencia Europea de Medio Ambiente 2000).

De la comparación entre países, aparte del diferencial de esfuerzo aplicado, la realidad ha evidenciado, como se ha subrayado, una discutible evaluación de partida en cuanto al rigor de los datos, a las expectativas y a la fiabilidad de los resultados esperados. En cualquier caso, resaltan significativamente las reducciones registradas, al término del período 1990-2000, en Luxemburgo (-28\%), y en Dinamarca y Alemania, ambas con el -21\%, que, de confirmar la tendencia en ambos países, podrán superar los objetivos de reducción. Por el contrario, España aparece en cabeza con una desviación al alza («indicador de distancia respecto al objetivo») del orden del $27 \%$, al contabilizar, para ese período, una subida del 34\%. Los datos más recientes para nuestro país dan una escalada próxima al 40\%. Por tanto, con las estimaciones actuales y el proceso tendencial constatado y sin políticas correctoras eficientemente aplicadas, puede afirmarse que habrá serias dificultades para el cumplimiento de los objetivos por parte española en compañía de Portugal, Grecia y Bélgica. En consecuencia, dos frentes serán próximamente testigos de la rendición de cuentas por parte española: por un lado, el «Comité de seguimiento», creado al amparo del Protocolo de Kyoto con objeto de comprobar el cumplimiento de las obligaciones asumidas, de tal manera que la finalización de la verificación podrá desembocar en una declaración expresa y en la correspondiente sanción, y, por otra parte, las instituciones de la Comunidad Europea en función de la puesta en marcha de los mecanismos inherentes al control del cumplimiento de la legislación comunitaria. Las tareas internas de seguimiento de la ejecución y cumplimiento de los compromisos contraídos comenzarán, entre otros elementos, con el establecimiento de un «Sistema Nacional de Control» para estimar las emisiones y con la puesta 
en funcionamiento de un «Registro Nacional» para la contabilización de los diferentes tipos de «certificados de emisión». De lo anterior puede apreciarse la importancia de la fiabilidad y del rigor en el inventario periódico de emisiones (Sierra Ludwig 2004: 97-99). Actualmente, estos determinantes están en precario. Conviene recordar que los distintos borradores, elaborados en la anterior legislatura para fijar una estrategia española frente al cambio climático, apenas pasaron de una aproximación al diagnóstico y de una relación de intenciones, sin vinculación ejecutora alguna (Ministerio de Medio Ambiente 2000).

Los datos fiables más recientes (2003), coincidentes con la ampliación de la UE, constatan una evolución desigual por Estados miembros, aunque globalmente más satisfactoria. Los objetivos fijados para la Comunidad sólo incluyen a los anteriores Estados miembros -quince países- si bien, la mayoría de los nuevos socios se han comprometido a reducir sus emisiones en un 8\% respecto al año de referencia en el primer período (2008-2012) del Protocolo de Kyoto (Agencia Europea de Medio Ambiente 2005). Hungría y Polonia se han propuesto reducciones en torno a un 6\%, mientras que Chipre y Malta, al no estar vinculadas al Anexo I de la UNFCCC, no han presentado objetivos al respecto. Según estos datos, un grupo de trece países comunitarios se sitúa con opciones desfavorables para el cumplimiento de los compromisos en el reparto de la carga, en el que destacan negativamente Irlanda, Portugal y España (Cuadro 1, p. 44). La observación de la distribución sectorial, permite resaltar una quiebra de la tendencia general por emisiones procedentes del transporte. Esta circunstancia se ha detectado en Alemania (tres años consecutivos) y Reino Unido, precisamente a causa de la aplicación de «medidas complementarias y combinadas» al buscar el cumplimiento de los objetivos a través de la conjunción de tres políticas concretas, tendentes a la obtención de: mayores rendimientos de los carburantes, aumento de la elasticidad de precios para influir en la demanda y diversificación en la utilización de medios de transporte. El Gráfico 1 recoge la distribución sectorial de las emisiones de gases de «efecto invernadero», en la Unión Europea, al término de 2003. Como puede apreciarse, en dicho año -último ejercicio con datos definitivos- la generación de electricidad y la producción de calor alcanzan del orden del 30\% de las emisiones de gases de efecto invernadero. La emisión conjunta de esas fuentes y las procedentes del transporte rodado rebasan el 50\% en la UE. Estas dimensiones otorgan un particular relieve a las estrategias que se arbitren para su reducción.

Por otro lado, en cuanto al papel de los «sumideros», reconocido por el Protocolo de Kyoto, pese a las potenciales y posibles aplicaciones al efecto del Inventario Forestal Nacional, la realidad internacional ha impuesto la necesidad de la elaboración por el IPCC de instrumentos específicos para la aplicación de criterios homogeneizados en orden a la estimación, seguimiento e información sobre las valoraciones del carbono almacenado y de las emisiones por fuentes y absorciones. La actual situación precisa de una correcta sistematización semántica que sea asumida generalizadamente, especialmente en materia de degradación de los bosques y de eliminación antropogénica de vegetación. A pesar de los diferentes intentos en la revisión, la uniformalización metodológica sigue en precario. De ahí, además, desde una perspectiva interna, la importante tarea pendiente en orden a: la potenciación de actuaciones favorables a mantener o mejorar la biodiversidad, incorporar la multifuncionalidad y la transversalidad conceptual y aplicada y al diseño de una estrategia expresamente canalizada a la reorientación de las diferentes políticas sectoriales convencionales. En estos momentos, con los instrumentos actuales y con la evidencia empírica disponible, cualquier estimación que se realice en nuestro país sobre la potencialidad de absorción por parte de los sumideros y que sobrepase el 3\% del volumen total de emisiones, sería utópica y excesivamente especulativa. Para el conjunto de la UE-15, según datos a comienzo de 2002, el efecto succión de los «sumideros» apenas ha alcanzado el 0,3\% de las emisiones del año base (1990).

El Protocolo de Kyoto, además de prever el acceso al mercado de derechos de emisión de gases de efecto invernadero, contempla otros mecanismos instrumentales, como la Aplicación Conjunta (AC) y el Mecanismo de Desarrollo Limpio (MDL). La justificación de estos tres mecanismos radica en que las emisiones de gases de efecto invernadero afectan a todos los países, por su incidencia global, con independencia del lugar de origen. Ambos 


\section{CUADRO 1}

Emisiones de gases de efecto invernadero en equivalentes de $\mathrm{CO}_{2}$ y objetivos respecto al Protocolo de Kyoto para el periodo 2008-2012

\begin{tabular}{|c|c|c|c|}
\hline Estados de la UE & $\begin{array}{l}\text { Año base: } 1990 \\
\text { (Mill.Tn) }\end{array}$ & $\begin{array}{c}\text { Variación } 2003-1990 \\
\text { en la UE } \\
(\%)\end{array}$ & $\begin{array}{c}\text { Objetivos } 2008-2012 \\
\text { respecto al Protocolo de Kyoto } \\
\text { y al reparto de la carga } \\
(\%)\end{array}$ \\
\hline & (1) & & \\
\hline Austria & 78,5 & 16,6 & $-13,0$ \\
\hline Bélgica & 146,8 & 0,6 & $-7,5$ \\
\hline Dinamarca & 69,6 & 6,3 & $-21,0$ \\
\hline Finlandia & 70,4 & 21,5 & 0,0 \\
\hline Francia & 568,0 & $-1,9$ & 0,0 \\
\hline Alemania & $1.248,3$ & $-18,5$ & $-21,0$ \\
\hline Grecia & 111,7 & 23,2 & $+25,0$ \\
\hline Irlanda & 54,0 & 25,2 & $+13,0$ \\
\hline Italia & 510,3 & 11,6 & $-6,5$ \\
\hline Luxemburgo & 12,7 & $-11,5$ & $-28,0$ \\
\hline Países Bajos & 213,1 & 0,8 & $-6,0$ \\
\hline Portugal & 59,4 & 36,7 & $+27,0$ \\
\hline ESPAÑA & 286,1 & 40,6 & $+15,0$ \\
\hline Suecia & 72,3 & $-2,4$ & $+4,0$ \\
\hline Reino Unido & 751,4 & $-13,3$ & $-12,5$ \\
\hline UE-15 & $4.525,5$ & $-1,7$ & $-8,0$ \\
\hline Chipre & 6,0 & 52,8 & $-(3)$ \\
\hline R.Checa & 192,1 & $-24,3$ & $-8,0$ \\
\hline Estonia & 43,5 & $-50,8$ & $-8,0$ \\
\hline Hungría & 122,2 & $-31,9$ & $-6,0$ \\
\hline Letonia & 25,4 & $-58,5$ & $-8,0$ \\
\hline Malta (2) & 2,2 & 29,1 & $-(3)$ \\
\hline Polonia (2) & 565,3 & $-32,1$ & $-6,0$ \\
\hline Eslovaquia & 72,0 & $-28,2$ & $-8,0$ \\
\hline Eslovenia & 20,2 & $-1,9$ & $-8,0$ \\
\hline
\end{tabular}

(1) UE-15: el año base es 1990 para $\mathrm{CO}_{2}, \mathrm{CH}_{4}$ y $\mathrm{N}_{2} \mathrm{O}$.

(2) Sin datos para 2003. Los de Malta y Polonia son estimaciones.

(3) Malta y Chipre no cuentan con compromisos en el Protocolo de Kyoto.

Fuente: AEMA.

facilitarán a los países industrializados y, por tanto, principales causantes del mayor volumen de emisiones, el cumplimiento de sus compromisos de reducción a través de proyectos ejecutados en otros países.

La Aplicación Conjunta (AC) se desarrolla en países industrializados con objetivos enmarcados en los compromisos del Protocolo, mientras que el Mecanismo de Desarrollo Limpio (MDL) se aplica en los demás países, es decir, en aquellos no sometidos a los acuerdos signados en Kyoto. El soporte básico de la AC y del MDL es similar al de los «derechos de emisión» ya que el protagonismo no reside en un carácter monolítico respecto al lugar de emisión y adquiere un importante papel la transferencia de tecnologías. Las iniciativas en los Estados 


\section{GRÁFICO 1}

Distribución sectorial de las emisiones de gases de efecto invernadero en la Unión Europea (Año 2003)

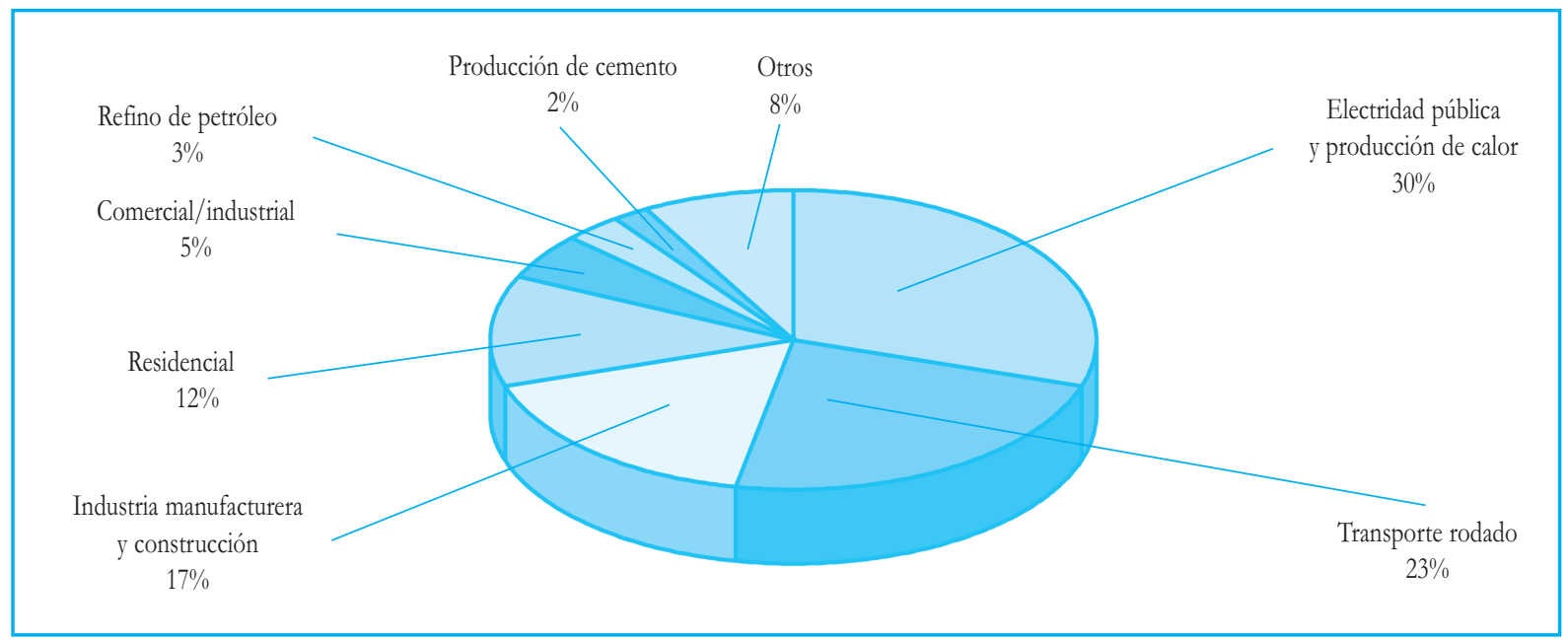

más activos para afrontar el problema y aprovechar las sinergias resultantes han propiciado actuaciones claras para el desarrollo de estos instrumentos. En esta línea figuran los acuerdos suscritos con el Banco Mundial para descontar determinados volúmenes de emisiones de $\mathrm{CO}_{2}$.

La creación de diferentes figuras (Fondo Prototipo de Carbono, Fondo de Carbono para el Desarrollo Comunitario y el Bio Carbon Fund del Banco Mundial), que tienen en común la instrumentación mercantil y financiera, se ha arbitrado, paralela y complementariamente a las exigencias del Protocolo de Kyoto, facilitando, por otra parte, la creación de empresas para asesoramiento, diseño, negociación, ejecución y creación de proyectos. (Sierra Ludwig 1996).

\subsection{Los derechos de emisión de gases de efecto invernadero y sus implicaciones económicas}

\section{- Discrepancias en la evaluación de los efectos económicos}

Pese a que el concepto «permisos» está adecuadamente establecido en la jerga de la legislación medioambiental comunitaria (tratamiento de residuos y contaminación acuática y de la atmósfera, principalmente), las directivas no pueden garantizar un resultado ambiental predeterminado. Este es el caso, por ejemplo, en emisiones de contaminantes a la atmósfera. Así, en las circunstancias asociadas a la creación de nuevas instalaciones industriales, la generación de efluentes puede ser superior a las previsiones, incluso en concordancia con el cumplimiento de las normas técnicas más estrictas. Con el mecanismo de «comercio de derechos de emisión» se facilita que las empresas superen cuotas de emisiones a condición de encontrar otros responsables emisores que no hayan superado los límites permitidos. La lógica económica del comercio de derechos de emisión reside en el uso de mecanismos de mercado para alcanzar reducciones y conseguir resultados ambientales predeterminados.

Los «derechos negociables» en la Unión Europea, aunque de escasa presencia en el ámbito medioambiental, han surgido en algunas políticas subsectoriales. Esto es así, por ejemplo, en la aplicación del Protocolo de Montreal al establecerse cuotas de producción y consumo asignables a empresas individuales en función de los niveles históricos de producción, en la distribución de cuotas lecheras de la Política Agrícola Común y en las cuo- 
tas de pesca en el contexto de la Política Pesquera Común con la opción, entre otras alternativas, de realizar transferencias entre Estados miembros.

La aprobación de la Directiva 2003/87 establece, con carácter general, un régimen para el comercio de los derechos de emisión de gases de efecto invernadero. Transcurrido el plazo límite fijado por la legislación comunitaria, se aprobaba el Plan Nacional de Asignación de Derechos de Emisión de España para el período 20052007. El mercado de derechos negociables se aproxima al 40\% de las emisiones totales. Es evidente que con las referencias de partida, el principal esfuerzo recaerá en el período 2008-2012 y afectará fundamentalmente al sector eléctrico y a determinados subsectores industriales (cemento, refino de petróleo, siderurgia e industria cerámica, principalmente). La correcta asignación en los sucesivos períodos estará condicionada, entre otros factores, por el funcionamiento de las verificaciones, la eficiente instrumentación de la contabilización de los derechos de emisión y el adecuado ejercicio de la potestad sancionadora. Con estas referencias es evidente el importante protagonismo al que se hace acreedora una adecuada y específica evaluación de resultados. El Plan Nacional de Asignación de Derechos de Emisión deberá someterse a una evaluación específica y continua.

La Directiva 2003/87 obedece a la necesidad de que la Unión Europea reduzca sus emisiones de gases de efecto invernadero de manera eficaz en cuanto a la mayor minimización de costes y al cumplimiento con las obligaciones de la Convención Marco de las Naciones Unidas sobre el Cambio Climático y del Protocolo de Kyoto.

El comercio de derechos de emisión se erige en un medio de protección del medio ambiente y en un instrumento que pretende incidir imperceptiblemente en la alteración de las reglas de la competencia. Al elaborarse el Programa Europeo sobre el Cambio Climático, el comercio de derechos de emisión fue objeto de amplios debates y análisis que han contribuido a un mejor conocimiento del instrumento y de las opiniones de las partes afectadas en el protagonismo revisor. La elaboración del texto se ha fundado en el respaldo del apartado 1 del artículo 175 del Tratado. La cantidad total de emisiones de gases de efecto invernadero cubiertas por este régimen es claramente limitada. Además, las instalaciones podrían dedicarse al comercio de derechos de emisión a escala comunitaria. Esta posibilidad es el elemento fundamental para aprovechar el potencial disponible de reducción eficaz y menos costosa de las emisiones. El beneficio de unas reducciones comparativamente menos costosas se pondrá a la disposición de otros en la Comunidad que podrían no disponer de posibilidades de reducción a menores costes, de manera que el intercambio de derechos de emisión «beneficiará» inicialmente a los protagonistas en las negociaciones dentro del mercado establecido (Comisión Europea 2005).

La justificación económica de un régimen comunitario ha estado respaldada por varios estudios que han facilitado las prioridades valorativas en función de «criterios de eficacia». En esta línea se han pronunciado las evaluaciones y estimaciones aplicadas a partir de la utilización de los modelos «Primes» $\mathrm{y}$ «Poles». Han sido determinantes, además, las aseveraciones centradas en un régimen comunitario al suponer una reducción comparativamente favorable en materia de distorsiones de la competencia y en lo referente a los posibles obstáculos al mercado interior que podrían aparecer a consecuencia del establecimiento de varios regímenes de comercio distintos y, por tanto, diversos precios del carbono en la Unión Europea. De ahí que una condición previa para el intercambio de emisiones resida en la aceptación por las entidades participantes de la limitación de las emisiones. Los «costes de adaptación asociados» encontrarán «efectos paliativos» por el comercio de los derechos de emisión al facilitar reducciones a través de una mejor relación coste-eficacia.

La razón fundamental del régimen de comercio de derechos de emisión gira en torno a la función de impulsar descensos de las emisiones necesarias para lograr unos resultados fijados previamente y a la obtención de costes comparativos más bajos. El comercio de derechos de emisión permitirá a algunas empresas emitir más de lo previsto por una fórmula que no se basa en topes lineales y rígidos ya que con este régimen podrán com- 
pensar globalmente las emisiones resultantes al amparo de otras que no hayan cubierto sus cupos y en disposición a transferir los derechos de emisión ahorrados. En consecuencia, el resultado medioambiental equivaldría a un cumplimiento de los compromisos globales. La Comunidad emitiría el mismo número de toneladas previsto por el Protocolo de Kyoto, pero se ajustarían los derechos de cada país. De ahí se desprende la importancia del rigor en los inventarios nacionales conexos no sólo para la titularidad de derechos de emisión y el seguimiento de su comercio, sino también para el ajuste de los compromisos de los Estados miembros en virtud del Acuerdo de reparto de la carga. Estos inventarios nacionales conexos serán un componente fundamental del mecanismo comunitario de seguimiento establecido por la Decisión 93/389/CEE del Consejo, al hacer posible el seguimiento exacto de los derechos de cada Estado miembro en virtud del Acuerdo de reparto de la carga. Es más, los inventarios nacionales deberán proporcionar información sobre el derecho de emisión de los sectores dedicados al comercio en cada Estado miembro y servirán así para controlar el cumplimiento de los compromisos, tanto por la Comunidad Europea como por los distintos países.

Las evaluaciones realizadas sobre las implicaciones y consecuencias económicas cuentan con unas elevadas discrepancias en los resultados, tanto por el confusionismo generado en ocasiones al elegir unas determinadas prospecciones sin la adecuada concreción y acotación del campo analizable como por la sistematización y la metodología adoptadas, que dificultan la asunción de un análisis de partida correcto y fiable.

Por un lado, destacan los estudios auspiciados por los Servicios de la Comisión de las Comunidades Europeas. Con anterioridad al planteamiento de la puesta en marcha de un mercado de emisiones negociables, a partir de diferentes marcos metodológicos, se analizaron las ventajas de un sistema de estas características. El análisis realizado se basó en el Modelo Primes, relativo a los sistemas energéticos de la UE. Los supuestos barajados llegaban a la conclusión de que si cada Estado miembro consiguiese cumplir los objetivos derivados del reparto nacional de las cargas para el cumplimiento del Protocolo de Kyoto, el coste anual a escala comunitaria se situaría en torno a 9.000 millones de euros hasta el año 2010. En cambio, de arbitrarse estrategias asentadas en un «mercado de derechos de emisión» se obtendrían resultados con menor coste. Así, considerando dos alternativas: para una particular aplicación por el sector de abastecimiento energético (producción de energía eléctrica, cogeneración, refinerías y grandes calderas de combustión) y por las industrias intensivas en consumo energético (industria siderúrgica, industrias de metales no férreos, materiales de construcción, productos químicos e industrias papeleras y de pasta de papel), los montantes se situarían alrededor de 6.900 millones de euros; y para una aplicación únicamente centrada en los productores de energía, el coste anual sería ligeramente superior a 7.200 millones de euros. Según dichas estimaciones, el «precio de los derechos de emisión» se elevaría a 33 euros por tonelada de dióxido de carbono, bien entendido que el coste para los demás sectores (agricultura, transporte, consumo residencial, servicios...) sería superior. Esta cota se sitúa en el margen analizado mediante otros modelos (AIM, G-Cubed, GTEM, MS-MRT, Oxford y SGM); si bien, las oscilaciones varían de 5 a 58 euros. En consecuencia, de acuerdo con estas proyecciones, la Comisión Europea llegaba a la conclusión de que el intercambio de los derechos de emisión a nivel comunitario desde ambos sectores (abastecimiento e industrias intensivas en consumo energético) permitiría una reducción del orden del 20\% de los costes respecto a una ausencia de esta formulación de implicación en el mercado ${ }^{1}$.

Recientes análisis, aplicados a la participación de los demás sectores excluidos en los anteriores estudios confirmaban una hipotética reducción de costes en torno al 34\% para el conjunto de la UE. A estas conclusiones llevaban las estimaciones llevadas a cabo por el Instituto de Estudios de Prospectiva Tecnológica y en Oxford por Economic Forecasting que utilizaron el Modelo Poles y un modelo macroeconómico, respectivamente. Según el

1 Para mayor información, véanse, entre otros, Capros y Mantzos (2000) y D. G. Joint Research Centre (2000). 
Modelo Poles, el comercio de los derechos de emisión extendido a todos los sectores de la UE reduciría el coste del cumplimiento de los compromisos de Kioto en un $25 \%$ en contraste con la hipótesis de ausencia de un sistema de intercambio entre los Estados miembros. El precio de los derechos de emisión ascendería a 49 EUR por tonelada de $\mathrm{CO}_{2}$. Estos resultados han confirmado la reducción del coste de cumplimiento y el precio de los derechos de emisión, habida cuenta de las diferencias entre los Modelos Poles y Primes. Por ejemplo, el Modelo Poles se refiere solamente a cuatro Estados miembros (los demás están reunidos en dos grupos) y contiene un reparto sectorial más limitado respecto al Modelo Primes. Paralelamente, el modelo macroeconómico de Oxford, ha confirmado los mismos resultados (Oxford Economic Forecasting 2002). Las diferentes hipótesis barajadas a partir de las contrastaciones entre estas estimaciones han coincidido en la posibilidad de una infrautilización de los impactos reales del sistema de derechos de emisión, precisamente en razón directa a que los modelos aplicados presuponen, con escasa base en la realidad, que los Estados miembros obtendrían cuotas de reducción por sí mismos y con el mayor ahorro a partir, entre otros mecanismos, de la aplicación de instrumentos fiscales, cargando a las emisiones de $\mathrm{CO}_{2}$, y de intercambios de derechos únicamente dentro de cada Estado miembro. De acuerdo con las conclusiones de los estudios sometidos a este tipo de hipótesis, los costes anuales para el cumplimiento de las obligaciones contraídas se dispararían a 20.000 millones de euros (Comisión de las Comunidades Europeas 2000). En España, las trayectorias y las propias conclusiones prospectivas obtenidas han estado condicionadas, en algunos casos, por el interés patrocinador de los propios estudios y han reflejado claras diferencias en contraste con análisis procedentes del mundo académico².

Sorprende que, en contraste con las iniciativas arbitradas en nuestro entorno comunitario, no hayan sido realizadas en nuestro país, o hechas públicas, estimaciones que recojan otros costes por no intervención (incluso, con el respaldo de «valoraciones económicas» en aplicación de determinadas técnicas y modelos emergentes) y reflejados en los efectos económicos, sociales y medioambientales inducidos a causa del cambio climático por la carencia de intervenciones reactivas y expresas. Todos los costes analizados o, al menos, publicados en España, se limitan a evaluaciones en función de la eliminación del excedente de $\mathrm{CO}_{2}$, sin profundizar en los costes y beneficios de las medidas de reducción o los beneficios asociados con el uso de los mecanismos flexibles, anteriormente mencionados. El carácter global, debido a la retroalimentación y a los efectos interactivos del fenómeno, adquiere tal complejidad y magnitud que resulta excesivamente fragmentaria la simple presentación de estimaciones en torno a costes económicos a corto plazo vinculados solamente al ajuste circunstancial provocado por el cumplimiento inmediato de obligaciones y compromisos contraídos. (Sierra Ludwig 2001).

Con estas referencias de base el marco de programación de inversiones y de ayudas públicas deberá ser sustancialmente revisado. La consideración de las implicaciones asociadas al ciclo vital de todo el proceso (materias primas, abastecimiento, producción, balanza comercial, demanda, residuos, contaminación, reservas, existencias disponibles, opciones...) exige necesariamente una profunda revisión de la Política de Ayudas Públicas y, paralelamente, facilitar la diversificación de opciones, de manera que pierda peso relativo el esfuerzo canalizado prioritariamente a través de las subvenciones.

\section{- Interacciones y sinergias}

El comercio de derechos de emisión y la política fiscal energética orientada a las emisiones de dióxido de carbono aconsejan un planteamiento complementario y una adecuada revisión de figuras instrumentales en curso a lo ancho de toda la geografía comunitaria.

2 Para una aproximación a las principales controversias, véanse Pricewaterhouse Coopers (2004), Ocaña Pérez de Tudela (2003), Philip (2004) y Sierra Ludwig (2005). 
La existencia de diferentes acuerdos medioambientales en varios Estados miembros, canalizados al cumplimiento de objetivos ya fijados, exige una reconducción a fin de comprobar su compatibilidad con los principios rectores de la estrategia y el desarrollo de un comercio de derechos de emisión. Además, paralelamente, se debería facilitar la implementación específica en función de los objetivos inherentes al nuevo régimen de certificaciones y autorizaciones y de negociación mercantil de emisiones.

$\mathrm{El}$ «nuevo régimen» puede ser un elemento dinamizador de carácter sinérgico con los «mecanismos flexibles», la internacionalización de la empresas y las políticas de apoyo al comercio exterior y con otras disposiciones y estrategias. En este sentido, sobresale el cumplimiento de la Directiva 96/61, relativa a la prevención y el control integrado de la contaminación, que reforzará los esfuerzos en el logro de resultados. En una primera aproximación ex-ante se puede afirmar que la legislación comunitaria sobre los permisos negociables ha aprovechado las sinergias con la legislación existente, y en especial, con la Directiva IPPC.

\section{Costes y beneficios en la reducción de los efectos favorables al cambio climático}

La reducción de las emisiones causantes del efecto invernadero arrastra claros beneficios por la eliminación y reducción de daños de diferente índole (salud, bióticos, sistémicos...) y evita los perjuicios ocasionados por el cambio climático. Los beneficios potenciales dependen, por un lado, del rigor de una serie de estimaciones y de evaluaciones, como pueden ser, las relacionadas con la disponibilidad y el coste de las tecnologías de adaptación y las implementaciones de raíz política, y por otra parte, del grado de sensibilidad del clima a las concentraciones antropogénicas de los gases de efecto invernadero. De acuerdo con las recientes aportaciones del IPCC, en estos momentos, no existen todavía estimaciones rigurosas sobre la cuantificación de los beneficios generados por una estabilización de las concentraciones de los gases de efecto invernadero, desde una prospección basada en niveles (IPCC 2001a: 49-70). De ahí, por tanto, las dificultades para abordar este tipo de ensayos a escalas locales o regionales. No obstante, pese a las actuales incertidumbres científicas y económicas, el IPCC en su Segundo Informe de Valoración, sostenía que una subida de las temperaturas globales en torno a 2,5 grados, provocaría unos costes del orden del 1, $-2 \%$ del PIB global, con serias variaciones y oscilaciones en las repercusiones a escala regional. Asimismo, actualmente se constatan consecuencias económicas por el cambio climático: durante los últimos 20 años el Sector Seguros ha duplicado, en términos reales, la contabilización de las pérdidas económicas por presiones interdependientes entre los grados de desarrollo en ciertas áreas y las desfavorables repercusiones ambientales surgidas. A partir de los datos más fiables y de la evidencia empírica constatada (los riesgos asociados a las subidas del nivel del mar, el empeoramiento de la cantidad y de la calidad de las aguas disponibles, las perdidas de biodiversidad y de productividad, la reducción o el desplome de las capas polares de hielo y diferentes acontecimientos de carácter catastrófico, entre otros fenómenos ya detectados), permiten circular determinados temores e incertidumbres a medio y largo plazo (IPCC 2001b). Los efectos no afectarán linealmente: la cuenca mediterránea sentirá con mayor intensidad que en latitudes superiores el problema de la disponibilidad del recurso del agua, tanto para abastecimiento como fuente energética, por lo que los efectos en la competitividad serán heterogéneos y dispares. Por consiguiente, las cargas inducidas que afectan a los costes de mitigación, ocupan un lugar muy importante en este proceso.

En cuanto a la evaluación de costes, las dificultades actuales aconsejan un comportamiento prudente al abordar presumibles incidencias. Las medidas de mitigación arrastran reajustes de diverso tipo que pueden afectar significativamente al Sector de la Energía y a los Sistemas de Transportes. De ahí, la importancia de la coherencia entre políticas y objetivos. En este sentido, según estimaciones conservadoras del IPCC, en el período 
1990-2100, el crecimiento del PIB, a escala mundial, se vería afectado en un por un 0,03\% anual. Las reducciones ante un objetivo más ambicioso se elevarían al 0,06\% anual (IPCC 2000).

La Comisión de la UE también ha realizado estimaciones de costes a escala global a partir de una estabilización de las concentraciones en la atmósfera de gases de invernadero para valores de 550 ppmv. Para un análisis centrado en UE-25 y a partir de un esfuerzo generalizado a través de políticas expresamente canalizadas al logro de una reducción del 1,5\% a partir de 2012 , la incidencia en el PIB en al año 2025 se situaría en torno al 0,5\% por debajo del nivel que se lograría en ausencia de medidas específicas. En el supuesto de que la reducción de emisiones se proyectase unilateralmente por la UE en contraste con la pasividad del resto de países, los costes podría triplicarse, según estas estimaciones y en el supuesto de que tampoco se utilizasen los «mecanismos flexibles» del Protocolo de Kyoto. Las prospecciones realizadas a partir de un objetivo centrado en 650 ppmv, los costes girarían en torno a una cuarta de los precisados para la anterior hipótesis; si bien, los costes adicionales - difícilmente cuantificables pero superiores a los anteriores- aparecerían al elevarse la temperatura media global en unos 2 grados centígrados sobre los niveles preindustriales. En síntesis, para una Unión Europea de 25 miembros, siempre en función del papel adoptable por la aplicación de tecnologías más eficientes y de la senda elegida para el ajuste a corto plazo, los costes oscilarían entre un 0,2 y un 0,5 del PIB, tomando por referencia el año $2025^{3}$. En consecuencia, de estos estudios se desprende la importancia del uso de las tecnologías adecuadas como complemento al resto de medidas y de políticas expresamente adoptadas para conseguir un reajuste efectivo. De acuerdo con las conclusiones de los estudios auspiciados por la Comisión de la UE, la minimización de costes para mitigar los efectos climáticos necesitaría la asunción de las siguientes condiciones:

- Inclusión de todos los sectores y de todos los gases de efecto invernadero generados -directa e inducidamente- por acciones antropogénicas.

- Participación de todos los responsables de las emisiones e inmisiones resultantes a escala internacional.

- Integración sin restricciones en el mercado de emisiones y optimización en el uso de otras medidas flexibles, como el «Mecanismo de Desarrollo Limpio».

- Máxima eficiencia, coherencia y conexión de las sinergias con otros objetivos de la UE; en particular, en función de la referencia de la «Estrategia de Lisboa», la «Política de Seguridad en el Abastecimiento de la Energía», la «Estrategia de Desarrollo Sostenible», la reforma continua de la «Política Agrícola Común» y las «estrategias temáticas» de cada área.

En contra de la extendida propensión a desembocar en generalizaciones sobre las repercusiones en las empresas, desde una perspectiva lineal, sin la incorporación de paralelas modificaciones tecnológicas con repercusiones favorables a medio plazo, como consecuencia de la aplicación de estrategias y de medidas para paliar, reducir o estabilizar las emisiones, la realidad demuestra con nítida tozudez que los «efectos globales» de las políticas en el PIB ocultan grandes diferencias entre sectores, incluso a escala subsectorial y empresarial. Así, en el grupo de actividades altamente intensivas en la utilización de energía (químicas, hierro, acero y fabricación de determinados materiales para la construcción, entre otras) las diferencias a nivel empresarial son, en ocasiones, elevadas. Por el contrario, las actividades orientadas hacia la producción de equipos y tecnologías favorables a la reducción en la intensidad energética y al ahorro y a la eficiencia energética, en términos relativos contarán con claros beneficios comparativos. Estos cambios estructurales requerirán reasignaciones y redistribuciones de capital con incidencia en la redistribución sectorial del empleo y, por tanto, nuevos enfoques al abordar el marco de las contabilizaciones de costes.

${ }^{3}$ Véase Comisión de las Comunidades Europeas (2001), Hendriks et al. (2001), Blok et al. (2001) y AEMA (2004). 
Las estimaciones de Pacala y Socolow (2004), que han gozado últimamente de un eco de aceptación favorable, exponen a través de la aplicación de una serie de opciones tecnológicas la posibilidad de lograr reducciones potenciales anuales hasta el año 2050, del orden de 3,6 Gt de dióxido de carbono (Cuadro 2).

\section{CUADRO 2 \\ Opciones tecnológicas asumibles para alcanzar una reducción potencial de emisiones del orden de 3,6 Gt de $\mathrm{CO}_{2}$ anuales hasta 2050}

\begin{tabular}{|l|l|l|}
\hline \multicolumn{1}{|c|}{ Eficiencia y ahorro } & \multicolumn{1}{|c|}{ Electricidad y combustibles } & \multicolumn{1}{c|}{ Sumideros naturales } \\
\hline \multirow{3}{*}{$\begin{array}{l}\text { Mejora en la eficiencia vehicular } \\
\text { Eficiencia en edificios }\end{array}$} & $\begin{array}{l}\text { Sustitución de carbón por gas natural } \\
\text { Almacenamiento de } \mathrm{CO}_{2} \text { «capturado» en: } \\
\quad-\text { grandes instalaciones } \\
\text { - plantas de hidrógeno } \\
\text { - plantas de combustión sintética }\end{array}$ & $\begin{array}{l}\text { Reordenación y gestión forestal } \\
\text { Reconversión de suelos y usos }\end{array}$ \\
& $\begin{array}{l}\text { Fisión Nuclear } \\
\text { Energía eólica }\end{array}$ & \\
& Energía fotovoltaica & \\
& Hidrógeno renovable & \\
& Biofuels & \\
&
\end{tabular}

\section{Marco general de instrumentos aplicables en la política am- biental}

La dialéctica en torno a la utilización de «instrumentos económicos y fiscales» para la protección del medioambiente lleva más de veinte años en el candelero a raíz de la Conferencia internacional de la OCDE sobre Medio Ambiente y Economía, celebrada en 1984, al incidir en la necesidad de intensificar la eficacia de las estrategias medioambientales.

El eco de esta Conferencia no se hizo esperar tanto en el propio Parlamento Europeo como en la Comisión de la UE, así como desde determinadas tribunas académicas, para volver a resurgir con cierto ímpetu y, a la vez, con reiteración en la mutilación de los planteamientos teóricos y previos a la ejecución de medidas concretas. Como consecuencia del creciente desarrollo del acervo comunitario en materia medioambiental y, en especial, el insatisfactorio cumplimiento -incluso en la primera fase del ciclo que coincide con la transposición al marco jurídico de los diferentes Estados miembros de la UE-, se ha facilitado el apoyo a un abanico de discusiones sobre la noción de «instrumento económico» y su idoneidad para proceder a un desplazamiento de las reglamentaciones en favor de mecanismos transformadores de la producción y del comercio. De esta manera se ha buscado el asentamiento del principio de «quien contamina, paga» y la aparición de incentivos económicos y fiscales con objeto de canalizar el comportamiento de los agentes económicos hacia una integración de la componente ambiental en los procesos productivos y de mercado. En síntesis, la presencia de apoyos (directos e inducidos), desarrollados desigualmente, según Estados y objetivos sectoriales, se han sostenido en la interconexión de cuatro pilares fundamentales: incentivos financieros, libertad de adaptación del contaminante, intervención de los poderes públicos e intención de protección del medio ambiente. (Sierra Ludwig 2004). Los estudios inicialmente realizados en los países pioneros de este enfoque (Alemania, Estados Unidos, Francia, Italia, Holanda y 
Suecia, principalmente) convenían en la concurrencia de ciertas ventajas comparativas respecto a la legislación llevada a cabo hasta entonces; es decir, de raíz económica y de eficacia, al menos teórica y potencialmente, al destacar presuntas mejores opciones en:

1. La minimización de costes globales para la lucha contra las emisiones contaminantes. En esta línea, se sitúan las tendencias a igualar los costes marginales de depuración de las aguas residuales con los cánones correspondientes o los certificados (derechos) de contaminación.

2. La reducción de la contaminación, al establecer cargas en los costes y, en consecuencia, el fomento inducido a la introducción de cambios tecnológicos en la implantación de mejoras en los procesos descontaminantes y de nuevos productos en el mercado.

3. La flexibilidad de acción procedente de los poderes públicos, por cuanto las modificaciones de las cargas conllevan menos complejidad que la modificación de un texto legislativo y, por tanto, los márgenes de adaptación parecen más fáciles de llevar a cabo a corto plazo.

4. La captación de recursos financieros. En la mayoría de los supuestos, los instrumentos económicos aparecen determinantemente en la asignación y obtención de fondos.

Las diferencias internacionales en la concepción y aplicación de estos instrumentos han sido y siguen siendo considerables. Aquí también se podría enunciar una larga serie de condicionantes. A modo de síntesis, la diversidad de ritmos y, en especial, de estrategias, ha estado delimitada por:

- Los propios principios de base que sustentan tanto a las políticas medioambientales adoptadas como a las políticas económicas y sectoriales (los principios de integración y de armonización destacan sobremanera).

- La eficacia y la operatividad de los mecanismos de negociación, no sólo entre administraciones públicas (central, regional y local) sino entre los poderes públicos, el entramado empresarial y los consumidores.

- Las estructuras políticas estatales (por ejemplo: regímenes centralizados o sistemas federales).

- Las conexiones a nivel internacional (cooperación internacional, UE, Consejo Nórdico, etc.).

Aunque ha prevalecido una cierta diferenciación entre el marco legal y los demás instrumentos (llámense, económicos y/o fiscales...), la referencia básica se asienta necesariamente en el marco jurídico por lo que en lugar de insistir en la concepción sustitutoria parece más aconsejable enfatizar en la diversificación de opciones y en el carácter complementario de la pluralidad de instrumentos.

Pese a la discutible denominación, extendida progresivamente, que acompaña a las instrumentaciones fiscales con la genérica acepción de otras hipotéticas y diferenciadoras intervenciones de índole económico, la realidad ha impuesto la escenificación de otros instrumentos con la intención de modificar el mercado (oferta y demanda) de productos y servicios con incidencia en el medio ambiente.

La experiencia adquirida en algunos de los países de la OCDE indica que el éxito en la aplicación de los tributos medioambientales depende de factores relacionados con el coste administrativo, el vínculo entre «tributo» $\mathrm{y}$ «contaminación», la contribución de nuevas cargas a la neutralidad del sistema fiscal y el contexto estructural en el que se asienta la política fiscal de cada país (OCDE 2001). Los criterios adoptados hasta ahora no se han ajustado a la conjunción de bases interdependientes que, por otro lado, han servido de referencia para el acuerdo de principios asumidos en la UE. Se trata del cumplimiento de los principios expuesto en el Cuadro 3.

Además, sería conveniente asumir la necesidad de acompañar unas líneas estratégicas diáfanas, en especial, al profundizar en las evaluaciones (rigurosas y no fragmentarias ni especulativas) de los costes y de los beneficios al discutir las diferentes alternativas. De ahí, el papel preponderante, en la siguiente fase, de la armonización y conjunción de criterios tendentes al establecimiento de: 
- Un marco de objetivos claros y precisos.

- Un campo de aplicación bien definido.

- Un sistema simple de funcionamiento que rechace, a la vez, la excesiva simplicidad y la complejidad en la ejecución e implantación.

- La integración de la componente ambiental en las diferentes políticas sectoriales. Precisamente, uno de los objetivos fundamentales de los instrumentos económicos se debe dirigir hacia el reflejo de los «costes medioambientales» en los precios de los bienes y servicios, buscando la mayor aproximación posible a la internalización de costes.

- Mayor rigor y seriedad en la determinación de los costes-eficacia.

- Estimaciones rigurosas de las consecuencias económicas inducidas.

- Coherencia entre los principios rectores de las políticas económicas, tanto a escala nacional como internacional -especialmente, en las áreas comerciales y fiscales- y los correspondientes a la protección medioambiental.

CUADRO 3

\section{Principios a cumplir para la correcta aplicación de la política ambiental}

- Eficacia. Esto es, eficacia entendida como la capacidad de respuesta y de reacción por parte de los agresores del medio ambiente. Precisamente las funciones básicas de los instrumentos económicos y fiscales (ofrecer las condiciones indispensables para combatir la contaminación y para desplegar la innovación tecnológica y la sustitución de productos) no ha destacado adecuadamente ante los compromisos derivados de la aplicación de la legislación vigente.

- Eficiencia Económica. Particularmente como objetivo en orden a la asignación óptima de recursos y, por tanto, de minimización de «costes económicos» en coherencia con las exigencias de protección ambiental.

- Equidad. Al depender de la idoneidad en la toma puntual de decisiones pueden generarse «cargas suplementarias», en unos casos, e impactos distributivos de diferente repercusión. Así, por ejemplo, en los «permisos negociables», los efectos destributivos difieren según las líneas adoptadas en la asignación inicial de permisos.

- Implantabilidad y de Optimización de Costes. Estos es, facilidad de implantación y mínimos «costes administrativos» previos. Aquí, la situación de las estructuras legales y el funcionamiento institucional determinan el ritmo de adopción de medidas, por lo que el hermetismo a la innovación suele hallarse adherido a esquemas y comportamientos reflejados desde sistemas fiscales desnivelados en la aplicación de la equidad.

- Aceptabilidad. Este «principio», que sintetiza la viabilidad en la utilización de instrumentos económicos y fiscales, implica el desarrollo decisivo de los mecanismos de información en paralelo con los resultantes grados de rigor y de estabilidad en su aplicación.

El abanico de opciones, basado en la corrección mediante la utilización de instrumentos diferentes a los estrictamente normativos, abarca un amplio campo que va desde las inyecciones procedentes de la vía presupuestaria hasta el desarrollo de procedimientos fiscales (generales, específicos...) y de prácticas de control interno y de expansión y creación de mercados nuevos.

La síntesis, expresada en el Cuadro 4, refleja la variedad de figuras, así como las principales características y objetivos. La combinación y aplicación de las mismas cuenta con una elevada heterogeneidad en su utilización y aceptación por los distintos países miembros de la UE.

Los criterios básicos podrían ajustarse a la definición de un esquema gradual en el establecimiento de propuestas estratégicas para la implantación complementaria entre instrumentos. De esta manera, se facilitaría en el ámbito fiscal, la adopción, por un lado, de bases imponibles ajustadas a los criterios de representatividad, simplicidad y aceptabilidad y, por otra parte, de la necesaria modificación estructural en la carga fiscal, ya que se trata de incidir en el origen de los ingresos tributarios y no de incrementar el esfuerzo a escala global. La distribución de los ingresos fiscales en los principales países comunitarios se asienta fundamentalmente en el factor trabajo, al proceder de cargas dirigidas al empleo, en contraste con las de origen medioambiental que giran en torno al $10 \%$ en los países europeos de mayor nivel de renta per cápita (Alemania, Dinamarca, Suiza...). La relación comparativa interestatal entre flujos fiscales de origen ambiental y el conjunto de ingresos fiscales refleja una dispersión acusada. 
Instrumentos fiscales y de mercado para apoyar estrategias medioambientales

\begin{tabular}{|c|c|c|c|}
\hline \multicolumn{2}{|r|}{ Tipos } & Clases & Características y objetivos \\
\hline \multirow[t]{2}{*}{ Fiscales } & Canones & $\begin{array}{l}\text { De vertido } \\
\text { Por uso } \\
\text { Por servicio prestado } \\
\text { Sobre productos } \\
\text { Adiministrativos } \\
\text { Disuasorios }\end{array}$ & $\begin{array}{l}\text { Pagos sobre vertidos al entorno, calculados en función de la cantidad y/o calidad de los contaminantes. } \\
\text { Pagos destinados a cubrir costes del tratamiento colectivo o público de los desechos y deterioros. } \\
\text { Aplicados al precio de los productos contaminantes en la fase de fabricación o utilización o como contraprestación a la creación de un } \\
\text { servicio para su eliminación. } \\
\text { Dirigidos a compensar acciones de control y autorizaciones administrativas. } \\
\text { Constituye una variedad de los cánones «por productos» para fomentar o disuadir ciertas producciones o consumos con efectos negati- } \\
\text { vos en el entorno. }\end{array}$ \\
\hline & $\begin{array}{l}\text { Exenciones } \\
\text { y/o } \\
\text { deduciones }\end{array}$ & Incentivos ("gasto fiscal») & $\begin{array}{l}\text { Desgravaciones fiscales y deducciones lineales. } \\
\text { Aplicable en la «imposición directa». } \\
\text { Suele dirigirse a incentivar mejoras tecnológicas de equipamientos y de producciones y servicios favorables al entorno. }\end{array}$ \\
\hline Presupuestos & Inversiones directas & $\begin{array}{l}\text { Incentivación reales con cargo a } \\
\text { los presupuestos públicos (es- } \\
\text { tatales, regionales y locales) }\end{array}$ & $\begin{array}{l}\text { Inversiones directas por las autoridades competentes en mejora y adaptación infraestructural favorable a la protección y conservación } \\
\text { del medio ambiente. }\end{array}$ \\
\hline
\end{tabular}




\begin{tabular}{|c|c|c|}
\hline \multicolumn{3}{|c|}{$\begin{array}{l}\text { CUADRO } 4 \text { (conclusión) } \\
\text { Instrumentos fiscales y de mercado para apoyar estrategias medioambientales }\end{array}$} \\
\hline Tipos & Clases & Caracteríscas y objetos \\
\hline \multirow[t]{2}{*}{ Financieros } & Créditos blandos & Basados en tipos de interés inferiores a la tasa de mercado. \\
\hline & Gravámenes por incumplimiento & Combinan cánones y multas ante incumplimientos. \\
\hline Sistemas de consignación & Sobrecarga al precio & $\begin{array}{l}\text { Reembolsable al cumplir ciertas condiciones. } \\
\text { Funcionan con carácter voluntario de las empresas pero suelen apoyarse en textos estatutuarios. }\end{array}$ \\
\hline \multirow[t]{5}{*}{ Creaciones de mercados } & Derechos de emisiones & $\begin{array}{l}\text { Se trata de la creación de un mercado basado en la negociación de «derechos» a la emisión de contaminantes a través de un precio. } \\
\text { Fomenta la flexibilidad en la distribución contaminante y la fijación de volúmenes globales con tendencia a la baja. El control: cuan- } \\
\text { titativo. }\end{array}$ \\
\hline & Intervención del mercado & $\begin{array}{l}\text { Mantenimiento o estabilización del precio de ciertos productos o servicios. } \\
\text { Incentivación vía intervención a favor de criterios ambientales. }\end{array}$ \\
\hline & Etiquetaje & $\begin{array}{l}\text { «Etiqueta verde»: distintivo para el fomento del mercado de productos en armonización con el medio ambiente o, comparativamen- } \\
\text { te, menos agresores. }\end{array}$ \\
\hline & «Aplicación Conjunta» & Inversiones descontaminantes en países terceros con compromisos internacionales (Protocolo de Kyoto) \\
\hline & «Mecan. Desarrollo Limpio» & Inversiones en países en vías de desarrollo sin compromisos signados internacionalmente. \\
\hline Prácticas internas & Ecogestión y ecoauditorías & $\begin{array}{l}\text { Sometimiento a controles internos (ecogestión) y fomento de mercados y apoyo a la imagen. } \\
\text { Aplicación de normativas y técnicas específicas: ecoauditorías. }\end{array}$ \\
\hline
\end{tabular}


Por tanto, parece evidente que sin engarce entre los diversos instrumentos de apoyo para la acción (legales, presupuestarios, fiscales y de mercado), que se erigen en elementos fundamentales para el logro de la mayor eficacia del «efecto disuason», la implementación de nuevas estrategias podría seguir anclada en una fase todavía preliminar, incipiente, monocorde y dialécticamente reiterativa, que se viene arrastrando por carencias serias en las bases de datos y en la voluntad para la adopción de políticas concretas

\section{Análisis de evaluabilidad: Criterios de evaluación y límites en la estimación de costes}

Generalmente, cuando se aborda la estimación de los costes que arrastrará la aplicación de medidas medioambientales se suele recurrir a la aceptación de criterios lineales -y excluyentes- de los denominados costes económicos asociados a «la nueva situación». Esta consideración se extiende a importantes ámbitos de presión o de responsabilidad decisoria (privados, oficiales...) que desembocan en mutiladas conclusiones y en la evacuación de disposiciones específicas con implicaciones de diferente índole.

Paralelamente a la emergente aparición de valoraciones económicas aplicables a la temática medioambiental -y aisladamente utilizadas por las diferentes autoridades ambientales- existen otros costes, especialmente, por «no actuación» y por mantener una situación estructural sin intervención expresa para la reconducción y reconstrucción, que deberían acompañar a las evaluaciones de acomodación y ajuste a corto y medio plazo. Junto a costes ambientales inducidos -algunos, cuantificables monetariamente, otros, únicamente evaluables desde la referencia física y sistémica y, múltiples, de carácter intangible a corto plazo que arrastran evidencias empíricas (cortas en algunas casos, pero de tipo tendencial en la mayoría de las ocasiones y, por tanto, previsibles y no especulativas)- aparecen importantes «costes por daños en la salud», algunos de ellos, obviamente, sin opciones para la evaluación económica en función de las propias limitaciones analíticas de la economía convencional, y otros, cuantificables monetariamente dadas las repercusiones en los marcos asistenciales y en las específicas medidas sanitarias a adoptar expresamente.

El cambio climático cuenta con importantes referencias analíticas en esas direcciones que deberían ser tenidas en cuenta como parte del diseño procedimental aplicable en las estrategias y políticas sectoriales, presupuestarias, fiscales etc. Los daños generados se extienden no sólo a aspectos relacionados directamente con la salud, sino también a interacciones vinculadas a medios y producciones sectoriales, ecosistémicas, hidrológicas, energéticas, sociales e inherentes a la provocación de riesgos y siniestros de etiología inducida antropogénicamente. Las sistematizaciones metodológicas y los estudios resultantes de Cline (1992), Fankhauser (1995), Scheling, Goering, Kalkstein, Kunst, y Nordhaus (1991), entre otros, se erigen en una referencia significativa. Tanto las evaluaciones de Cline como las de Fankhauser para Estados Unidos, reflejan unos daños estimados ante la duplicación de las emisiones de $\mathrm{CO}_{2}$ no inferiores al 1\% del PIB y con claras repercusiones negativas en el Sector de Agricultura y en las disponibilidades de agua que confirman las previsiones procedentes del IPCC. Desde la perspectiva económica convencional, el III Informe de Evaluación del IPCC sostiene que el impacto de las medidas adoptables para el cumplimiento del Protocolo de Kyoto en la mayoría de los países desarrollados para el año 2.010 no alcanzaría el 1\% del PIB. Es más, con la aplicación del comercio de emisiones entre los países de la OCDE, los costes medios se situarían por debajo del $0,5 \%$ con oscilaciones que girarían dentro de un abanico que va del 0,1 al $1,1 \%$ (IPCC 2001c: 125-130). Por el contrario, Japón podría lograr un «crecimiento adicional inducido» del PIB del orden del 1\% a raíz del uso de incentivos para la innovación y la eficiencia energética. Incluso, estas estimaciones se deslizan hacia un crecimiento adicional e inducido, especialmente, en determinados países en vías de desarrollo de Asia y de Europa. Estas contradicciones ilustran la importancia de la incorporación en el análisis de un 
conjunto de variables con implicación en la alteración del marco estructural, desencadenante de las disfuncionalidades y contradicciones entre los objetivos sectoriales existentes. El cumplimiento del Protocolo de Kyoto en los países comunitarios, de acuerdo con las evaluaciones de Harmelink, Philipsen, Jager y Block, entre otros expertos, sería no sólo factible sino que se lograría con «insignificantes efectos económicos adversos» y, en algunos supuestos, con beneficios adicionales (Harmelink et al. 2001).

\section{El proceso de evaluación de resultados}

\section{1. Ámbitos de aplicación}

El seguimiento eficaz de los resultados de la gestión se erige en un componente fundamental para el conocimiento de la concordancia entre las previsiones y programaciones y el cumplimiento de objetivos como referencia para abordar los ajustes y las reformas necesarias. Para esta proyección debe contarse con instrumentos de gestión adecuados a partir del conocimiento de la realidad. La experiencia en el desarrollo de los sistemas de medición de resultados puede considerarse amplia y constituye una base para el diseño y aplicación de indicadores. Pero, como subraya Zapico, recogiendo las sugerencias expuestas por Booth -hace ya quince años- el análisis no puede sustituir al «juicio político» que, en ocasiones, trasciende en sus consideraciones al ámbito analítico porque imponderables de diferente tipo afectan a las propias decisiones. La elección de buenos y fiables indicadores han de responder a la conjunción de determinadas características que se ciñan, al menos, a: la propia validez, por su armonización con los objetivos buscados; la exactitud, desterrando ambigüedades o manipulaciones y buscando la precisión; y la utilidad a fin de regir inflaciones y complejidades innecesarias orientadas a la búsqueda de los fines perseguidos (Zapico 2000).

Las primeras andaduras en nuestro país, eso sí, muy limitadas en la forma y en el fondo por el contexto político y los medios existentes, se iniciaron con la «planificación indicativa», posteriormente, denominada «planificación deslizante»; pero apenas pasaron de una mera exposición de intenciones al amparo del cumplimiento de unos determinados objetivos que se antojaron irreales en su cumplimiento, tanto por la arbitrariedad de su elección, como por la etérea sistematización en la implementación de medidas e instrumentos ejecutores. Con la entrada en las Comunidades Europeas las perspectivas, desde una incipiente concepción a escala comunitaria, se han abierto hacia un mayor rigor, si bien, todavía en fases preliminares, aunque algunas, ambiciosas en su contextualización y en sus opciones. En este sentido, caben subrayar tres referencias -fragmentarias, parciales, pero significativas- que se extienden a los ámbitos estrictamente presupuestarios, a los fondos estructurales y al impacto ambiental.

Por lo que se refiere a los fondos estructurales, a partir de la experiencia adquirida por los comités de seguimiento, para el período de programación 2000-2006, se establecieron, dentro de una interesante metodología, unas series de indicadores para el seguimiento y evaluación, conforme a una «lógica de la intervención» que se expresa en el Gráfico 2. Al efecto, se aceptaron cuatro tipos de indicadores: de «recursos», en función de la atención presupuestaria; de «realización» en conexión con la actividad; de «resultados» a partir de los efectos directos e inmediatos generados; y de «impactos», tanto específicos como globales.

Por otro lado, desde la óptica presupuestaria se elaboraron guías prácticas para afrontar evaluaciones exante, intermedias y ex-post. Al respecto, hay que resaltar la clara connotación limitada de este tipo de ámbitos, sobre todo, al profundizar en el análisis y en la evaluación de políticas y estrategias sectoriales, cuyos resultados sobrepasan la simple consideración de meras programaciones y ejecuciones de gasto. Existen estrategias y políticas que no se apoyan fundamentalmente en los presupuestos públicos y, sin embargo, por su dimensión (económica, social, medioambiental...), alcance, objetivos y efectos de escala, aportan repercusiones multidimensionales y transversales de elevada importancia. 
En tercer término y, en parte, también conectadas con las implicaciones estructurales, aparecen las figuras relacionadas con las «evaluaciones de impacto ambiental». Aquí se distinguen tres modelos, también fragmentarios y parciales en su dimensión analítica, pero que han supuesto un avance en la contextualización integrada por la incorporación de la temática ambiental en el diseño de otras políticas. Se trata de: la «evaluación de impacto ambiental de proyectos», la «evaluación ambiental estratégica»-iniciada en Estados Unidos en 1969-, la «evaluación de las repercusiones ambientales de planes que puedan afectar a zonas especiales de conservación» (Directiva de Hábitats) y la «evaluación de los efectos de determinados planes y programas en el medio ambiente» (Directiva 2001/42, cuyo plazo límite para la transposición ha finalizado el 21 de julio de 2004). La importancia de la Directiva 2001/42 descansa en el intento de facilitar la integración de la componente ambiental en las demás políticas sectoriales y de poner un cierto orden en la hetereogeneidad de modelos existentes. La posibilidad de supervisar los efectos de la aplicación de los planes y programas en el medio ambiente aporta la novedad de poder identificar con tiempo los efectos adversos no previstos y permitir la implementación de medidas de reparación adecuadas.

En el Cuadro 5 se recogen los principales rasgos diferenciales en el contenido de los procesos que afectan a la Evaluación Ambiental Estratégica y a la Evaluación de Impacto Ambiental de Proyectos. Las principales diferencias entre ambos modelos se pueden distinguir a partir de cinco consideraciones. Por un lado, la EIA utiliza fundamentalmente datos cuantificados frente a la EAE que combina datos descriptivos con cuantificaciones diversas. Además los objetivos, en el primer caso, se asocian generalmente a puntos focales, identificados en su localización, mientras que la «perspectiva estratégica» se extiende a consideraciones globales, nacionales o regionales. Asimismo, la metodología aplicada para la predicción de impactos difiere sensiblemente en una doble dirección: en la EIA la base para la estimación se suele asentar en datos cuantificados y en una sistematización compleja, en contraste con las valoraciones aparentemente sencillas pero con altas dosis de incertidumbre en la EAE.

Los diferentes procesos que aparecen en las intervenciones vinculadas a los «Programas Comunitarios» exploran, en el marco de los objetivos generales, tanto los impactos a largo plazo y los resultados inmediatos, como la consecución de objetivos generales, específicos -a raíz de los efectos directos e inmediatos- y de carácter operativo, a partir de la correspondiente asignación de recursos engarzada con la correspondiente adopción de medidas. La profundización en el análisis de estos procesos arroja considerables divergencias en las actuaciones sectoriales y globales de los distintos Estados miembros en el ejercicio de sus competencias sometidas al cumplimiento del «Principio de Subsidiaridad» y distantes de las reglas procedimientales arbitradas en el seno de los servicios de la Comisión de la CE (Gráfico 2).

\section{CUADRO 5}

Diferencias entre evaluación ambiental estratégica y evaluación de impacto ambiental de proyectos

\begin{tabular}{|c|c|c|}
\hline & $\begin{array}{l}\text { Evaluación ambiental } \\
\text { estratégica }\end{array}$ & $\begin{array}{l}\text { Evaluación de impacto ambiental } \\
\text { (proyectos) }\end{array}$ \\
\hline Datos & Una combinación de datos descriptivos y cuantificados & Principalmente, datos cuantificados \\
\hline Objetivos/alcance de los impactos & Global, nacional y regional & Principalmente, local \\
\hline Opciones & $\begin{array}{l}\text { Por ejemplo: un uso más eficaz de las nfraestructuras } \\
\text { existentes, medidas diseño, etc. }\end{array}$ & Por ejemplo: localización, variantes técnicas, diseño, etc. \\
\hline Métodos de predicción de impactos & $\begin{array}{l}\text { Sencillos, basados en matrices y en la experiencia de } \\
\text { expertos. Alto nivel de incertidumbre }\end{array}$ & $\begin{array}{l}\text { Complejos, frecuentemente basados en datos cuantifi- } \\
\text { cados }\end{array}$ \\
\hline
\end{tabular}




\section{GRÁFICO 2}

Procesos en la intervención de un programa comunitario

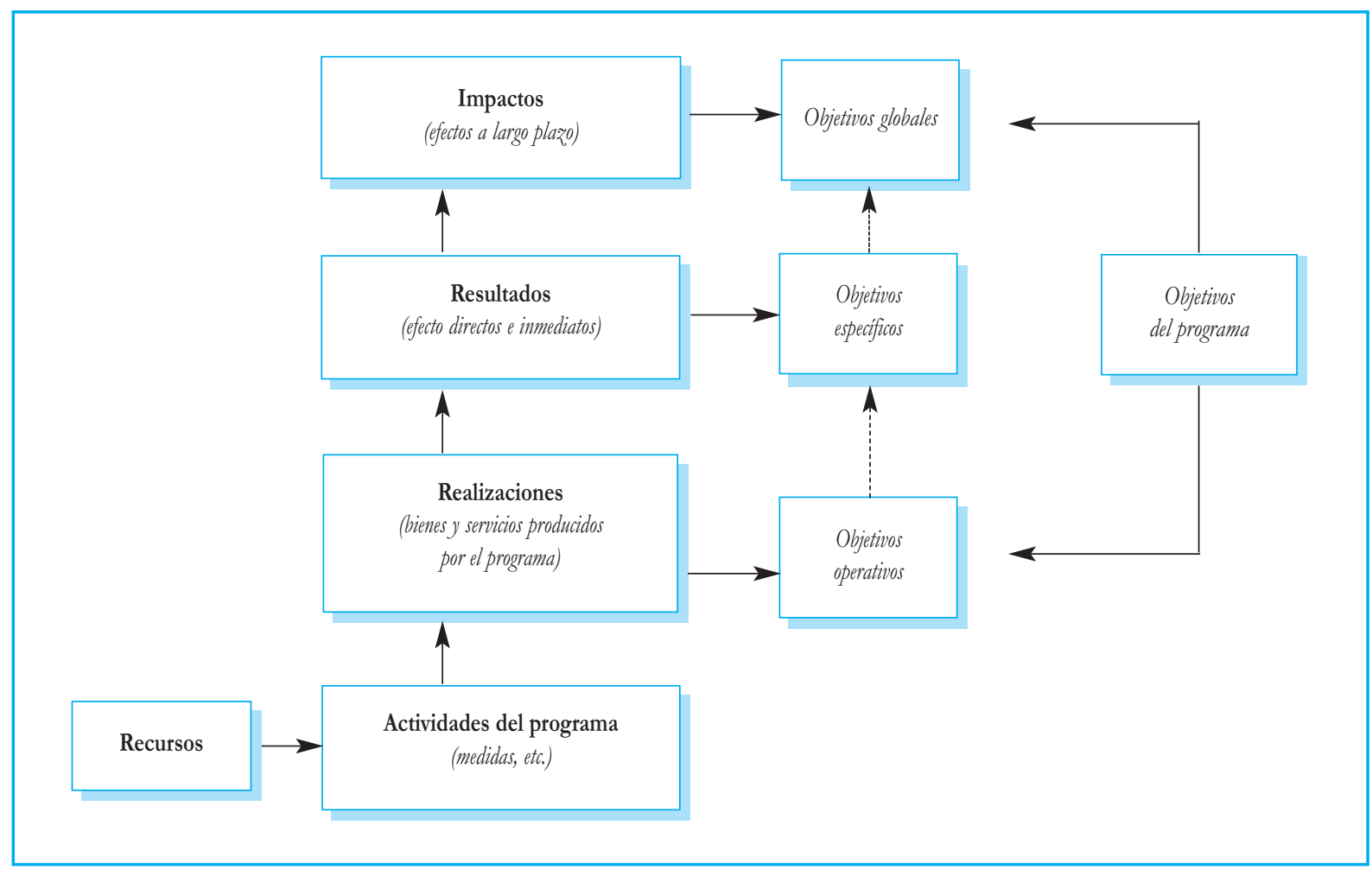

\subsection{Perspectivas para la aplicación al Protocolo de Kyoto}

Las figuras de evaluación descritas anteriormente presentan limitaciones en relación con el ámbito de aplicación: se refieren básicamente a impactos ambientales y despliegan sus esfuerzos principalmente en las fases de programación y se desgajan del análisis de otros efectos y resultados, por lo que reclaman la necesidad de orientaciones centradas en la última fase del proceso.

La Comisión de la Unión Europea, en un intento de aplicación a las emisiones de gases de efecto invernadero, en 1993 estableció, a escala comunitaria, un mecanismo de seguimiento de las emisiones antropogénicas y de evaluación de los progresos realizados, si bien, incompleto e intermitente, esto es, sin continuidad ni regularidad en la evaluación y sin descender al análisis de las medidas adoptadas 4 . Para subsanar estas deficiencias se aprobaba, recientemente, la Decisión 280/2004, con objeto de establecer un mecanismo para:

- el seguimiento de todas las emisiones antropogénicas por las fuentes y de la absorción por los sumideros de los gases de efecto invernadero no regulados por el Protocolo de Montreal, relativo a las sustancias que agotan la capa de ozono;

- evaluar los progresos realizados en el cumplimiento de los compromisos relativos a dichas emisiones por las fuentes y la absorción por los sumideros;

- aplicar la Convención Marco de las Naciones Unidas sobre el Cambio Climático (CMNUCC) y el Protocolo de Kyoto, en lo que respecta a los programas nacionales, los inventarios de gases de efecto invernadero, los sistemas nacionales y los registros de la Comunidad y los Estados miembros, así como los procedimientos pertinentes con arreglo al Protocolo de Kyoto, y

\footnotetext{
${ }^{4}$ Decisión 93/389.
} 
- garantizar la puntualidad, la integridad, la exactitud, la coherencia, la comparabilidad y la transparencia de la información presentada por la Comunidad y los Estados miembros a la secretaría de la CMNUCC.

En consecuencia, a partir de estos requisitos, los Estados miembros están obligados a elaborar y aplicar «Programas Nacionales»y no simples «estrategias» sin compromisos ni objetivos ejecutables. Asimismo, la Comisión de la UE está también obligada a elaborar y aplicar un «Programa Comunitario» revisable periódicamente. En ambos casos, se deberá contribuir, por un lado, a cumplir los compromisos de la Comunidad y de los Estados miembros en relación con la limitación o la reducción de todas las emisiones de gases de efecto invernadero, en virtud de la CMNUCC y del Protocolo de Kyoto, y, por otra parte, seguir, de forma transparente y precisa, los progresos efectivos y previstos de los Estados miembros, incluida la contribución aportada por las medidas comunitarias, en el cumplimiento de los compromisos contraídos por la Comunidad y los Estados miembros en relación con la limitación y/o reducción de todas las emisiones de gases de efecto invernadero de acuerdo con la CMNUCC y el Protocolo de Kyoto.

La «evaluación de los progresos previstos» corresponderá a la Comisión, por lo que en marzo de 2005 y a partir de esa fecha cada dos años, los Estados miembros deberán transmitir una amplia información que forzará, en el caso español, a profundos reajustes procedimentales, técnicos y administrativos para abordar las nuevas exigencias. De las carencias actuales da idea la mera exposición descriptiva de los contenidos a determinar y comunicar a la Comisión antes del 15 de enero de cada año, que se recoge en el Cuadro 6.

\section{CUADRO 6}

\section{Elementos a determinar y comunicar a la comisión para la «evaluación de los progresos realizados»}

Los Estados miembros de la UE, para evaluar los progresos realizados y permitir la elaboración por la Comunidad de los informes anuales, de conformidad con las obligaciones contraídas en virtud de la CMNUCC y del Protocolo de Kyoto, el 15 de enero de cada año, determinarán y comunicarán a la Comisión:

a) sus emisiones antropogénicas de los gases de efecto invernadero enumerados en la lista del anexo A del Protocolo de Kyoto [dióxido de carbono $\left(\mathrm{CO}_{2}\right)$, metano $\left(\mathrm{CH}_{4}\right)$, óxido nitroso $\left(\mathrm{N}_{2} \mathrm{O}\right)$, hidrofluorocarbonos $(\mathrm{HFC})$, perfluorocarbonos $(\mathrm{PFC})$ y hexafluoruro de azufre $\left.\left(\mathrm{SF}_{6}\right)\right]$ durante el penúltimo año;

b) los datos provisionales de sus emisiones de monóxido de carbono (CO), dióxido de azufre $\left(\mathrm{SO}_{2}\right)$, óxidos de nitrógeno (NOx) y compuestos orgánicos volátiles (COV) durante el penúltimo año, junto con los datos definitivos del año antepenúltimo;

c) sus emisiones antropogénicas de gases de efecto invernadero por las fuentes, así como la absorción de dióxido de carbono por los sumideros derivada del uso del suelo, del cambio del uso del suelo y de la silvicultura durante el penúltimo año;

d) información relativa a la contabilización de las emisiones y absorciones derivadas del uso del suelo, del cambio del uso del suelo y de la silvicultura, de conformidad con el apartado 3 del artículo 3 de la Decisión 280/2004, y cuando el Estado miembro decida hacer uso de él, del apartado 4 del artículo 3 del Protocolo de Kyoto, así como con las decisiones pertinentes, en los años comprendidos entre 1990 y el penúltimo año;

e) cualquier modificación de los datos a que se refieren las letras a) a d) relativa a los años comprendidos entre 1990 y el año antepenúltimo;

f) los elementos de los informes de los inventarios nacionales necesarios para la elaboración del informe del inventario comunitario de los gases de efecto invernadero, como la información sobre el plan nacional de garantía y control de la calidad, una evaluación general de incertidumbre, una evaluación general de la integridad e información sobre los nuevos cálculos realizados;

g) información procedente del registro nacional, una vez establecido, sobre la expedición, la adquisición, la titularidad, la transferencia, la cancelación, la retirada y el arrastre de las unidades de la cantidad atribuida, de las unidades de absorción, de las unidades de reducción de emisiones y de las reducciones certificadas de emisiones;

b) información sobre las personas jurídicas autorizadas a participar en los mecanismos previstos en los artículos 6, 12 y 17 del Protocolo de Kyoto, en cumplimiento de las disposiciones nacionales o comunitarias aplicables;

i) las medidas adoptadas para mejorar las estimaciones, por ejemplo en caso de que algún sector del inventario haya sido objeto de ajuste;

j) información sobre los indicadores del penúltimo año.

k) cualquier modificación del sistema de «inventarios nacionales».

(A más tardar el 15 de marzo de cada año, los Estados miembros comunicarán a la Comisión los «informes completos» de los «Inventarios Nacionales»). 
Asimismo, los Estados miembros de la UE, para ser evaluados los progresos previstos, están obligados a transmitir a la Comisión, el 15 de marzo de 2005, y cada dos años a partir de esta fecha, una amplia y compleja información, de cuya dimensión y trascendencia da cumplida muestra el Cuadro 7.

\section{CUADRO 7 \\ Contenidos de la información a transmitir a la comisión para realizar la periódica evaluación de los progresos previstos}

1) Información sobre las políticas y medidas nacionales que limiten o reduzcan las emisiones de gases de efecto invernadero por fuentes o que aumenten la absorción por los sumideros, presentada por sectores y por cada gas de efecto invernadero, que incluirá:

a) el objetivo de las políticas y las medidas;

b) el tipo de instrumento por cada política;

c) el estado de la aplicación de la política o medidas adoptadas;

d) los indicadores de seguimiento y evaluación de los progresos obtenidos con las políticas y medidas;

e) previsiones cuantitativas de la repercusión de las políticas y medidas en las emisiones por fuentes y la absorción por los sumideros de los gases de efecto invernadero entre el año de base y los años posteriores, incluidos 2005, 2010 y 2015, con referencia a sus repercusiones económicas en la medida en que sea factible, $y$

f) en qué medida la acción interna constituye realmente un elemento significativo del esfuerzo realizado a escala nacional, y en qué medida la utilización de los mecanismos de aplicación conjunta, de desarrollo limpio y del sistema de intercambio internacional de derechos de emisión es realmente complementaria de las medidas internas con arreglo a las disposiciones correspondientes del Protocolo de Kyoto y de los Acuerdos de Marrakech.

2) Información sobre las previsiones nacionales de emisiones de gases de efecto invernadero por fuentes y su absorción por los sumideros como minimo para los años 2005, 2010, 2015 y 2020, presentadas por gases y sectores; que incluirán:

a) previsiones «con medidas» $\mathrm{y}$ «con medidas adicionales», tal como se indican en las orientaciones de la CMNUCC y se especifican en las disposiciones de aplicación adoptadas por la Decisión 280/2003;

b) una descripción clara de las políticas y de las medidas incluidas en las previsiones,

c) los resultados del análisis de sensibilidad realizado para las previsiones y

d) la descripción de las metodologías, los modelos, los supuestos básicos y los parámetros input-output principales.

3) Información sobre las medidas que se están adoptando o están previstas para la aplicación de la legislación y las politicas comunitarias, e información sobre las medidas legales e institucionales para preparar el cumplimiento de los compromisos contraídos en virtud del Protocolo de Kyoto, así como información sobre las medidas adoptadas y la aplicación nacional en relación con los procedimientos de cumplimiento y ejecución;

4) Información sobre los acuerdos institucionales y financieros y sobre los procedimientos de toma de decisiones para coordinar y apoyar las actividades relacionadas con la participación en los mecanismos previstos en los artículos 6, 12 y 17 del Protocolo de Kyoto, incluida la participación de personas jurídicas

De la importancia del contenido y del alcance del «mecanismo de seguimiento» creado, se deduce el considerable esfuerzo que deberá abordarse y que, en función de las propias limitaciones de la perspectiva horizontal arbitrada entre departamentos, requerirá, probablemente, de una proyección de índole vertical y diferente a las convencionales vinculaciones interministeriales. De ahí, el carácter imprescindible y prioritario a favor de unos rigurosos diagnósticos previos para abordar «análisis de evaluación» que recojan las incoherencias y las contradicciones entre las diferentes estrategias y políticas sectoriales (energéticas, infraestructuras viarias, transportes, agricultura, forestales, residuos, turismo...) y departamentales, actualmente en ejecución. La señalización y la evaluación de las desconexiones y disfuncionalidades existentes, constituye un marco de análisis imprescindible para la búsqueda de la coherencia y de la racionalidad en la programación y en la administración de recursos. El protagonismo de la futura «Agencia de Evaluación» puede llegar a ser clave para el análisis vertical apuntado y podrá evitar los sesgos y limitaciones procedentes de la dimensionalidad horizontal.

\section{Algunas reflexiones ante la evaluación de un entorno complejo}

El medio ambiente entraña ante todo una dimensión enormemente compleja por sus interconexiones sistémicas, las interrelaciones concatenadas y las implicaciones directas e inducidas de cuanto se realiza en los contextos 
bióticos, biotópicos y biocenóticos; especialmente, desde las decisiones y actuaciones antropogénicas que reflejan serios condicionantes en el curso patrimonial del entorno. Pese al pretendido antagonismo entre «economía» y «medio ambiente», las aportaciones alrededor de la sostenibilidad del desarrollo y de otros conceptos afines, apoyan este binomio como un componente a diseñar, analizar y a evaluar conjuntamente (Sierra Ludwig y Weidner, 2005).

Las referencias de esta nueva dimensión se han observado recientemente desde diferentes frentes de implicación internacional.

Por un lado, la Declaración de Río de Janeiro, adoptada en el seno de la Conferencia de Naciones Unidas sobre el Medio Ambiente y el Desarrollo en 1992, se ha erigido en la base conceptual y de principios a fin de conseguir que, con rango internacional, la política ambiental y las demás políticas económicas y sectoriales se entiendan, elaboren y apliquen de forma integrada, combinando las perspectivas económicas, sociales y medioambientales. A partir de ahí, se inicia la construcción de un replanteamiento del modelo.

Paralelamente, el Preámbulo del Programa 21 asociado a la Declaración de Río, presenta los problemas y retos de la sostenibilidad como un ámbito en el que se necesita de un consenso a escala mundial y de un compromiso político a nivel de la cooperación internacional para lo cual es imprescindible disponer de una importante base científica y de una secuencia progresiva de acuerdos y compromisos internacionales. De ahí, la importancia de los dos Acuerdos firmados: en primer término, el Convenio sobre la Diversidad Biológica, como instrumento marco para los convenios internacionales sobre conservación y cuyos objetivos fundamentales se ubican en el mantenimiento de la biodiversidad para el desarrollo sostenible y la participación equitativa en los beneficios derivados de la utilización de los recursos; y, en segundo lugar, el Convenio sobre el Cambio Climático, para lograr estabilizar las concentraciones de gases de efecto invernadero en la atmósfera y evitar las preocupantes consecuencias ante la modificación del sistema climático global. Posteriormente, como consecuencia de los acuerdos de Río de Janeiro, se firmaba en París, en junio de 1994, la Convención de las Naciones Unidas de Lucha contra la Desertificación para los países afectados por sequía o grave desertificación.

En la Comunidad Europea, se introduce el concepto de «desarrollo sostenible» en los textos comunitarios, incluyéndolo entre los principios fundamentales de la Unión. Con las modificaciones incorporadas a partir del Tratado de Ámsterdam, firmado en 1997, en el artículo 2 del Tratado de la Comunidad Europea, la anterior matización al desarrollo «armonioso y equilibrado» de las actividades económicas en el conjunto de la Comunidad se completa con la adición de la «sostenibilidad». Asimismo, se añade, dentro de las misiones de la Comunidad, la promoción de un «alto nivel de protección y de mejora de la calidad del medio ambiente». Esto ha supuesto un paso adelante con implicaciones irreversibles y progresivas en la readaptación de las estrategias sectoriales y, en consecuencia de la política legislativa comunitaria, conforme se ha venido comprobando en los últimos años.

Estas bases se trasladaron al Proyecto de Tratado por el que se instituye una Constitución Europea. A pesar de la actual «hibernación» de la Carta Magna, la irreversibilidad de la aceptación conceptual del «desarrollo sostenible» es evidente, al estar incluido dentro de los objetivos de la Unión y basarse su impulso no sólo en lo que se denomina un «crecimiento económico equilibrado» y en una economía social de mercado altamente competitiva, sino también en un «nivel elevado de protección y mejora de la calidad del medio ambiente», extendiéndose en sus relaciones con el resto del mundo a contribuir al «desarrollo sostenible del planeta». Por tanto, estamos, sin marcha atrás, ante otros enfoques y diferentes concepciones de desarrollo que se traducirán en revisiones de los planteamientos estratégicos y de políticas y en la incorporación de nuevas técnicas y de diferentes análisis sobre evaluabilidad. El futuro contexto legislativo comunitario, que se asentará en el establecimiento de «leyes» y «leyes marco» europeas, en materia ambiental -compartida competencialmente por la Unión con los Estados miembros, 
salvo en materia de conservación de los recursos biológicos dentro de la política pesquera común que seguirá siendo de competencia exclusiva de la Unión- aprobará Programas de Acción de carácter general que fijarán objetivos prioritarios a alcanzar. Sin perjuicio de determinadas medidas adoptadas por la Unión, los Estados miembros tienen y tendrán a su cargo la financiación y la ejecución de la Política Medioambiental.

Por otro lado, la Estrategia de la Unión Europea para un Desarrollo Sostenible se adoptaba en el Consejo Europeo de Gotemburg, celebrado en junio de 2001. Esta Estrategia se basaba en la selección de cuatro prioridades, como primer paso para la orientación futura de las políticas (cambio climático, transportes, salud pública y recursos naturales) y ha estado precedida de una importante tarea de reflexión y de integración del concepto de desarrollo sostenible en las políticas y en los instrumentos comunitarios, así como de numerosos estímulos para su puesta en práctica ${ }^{5}$. Cabe destacar, a este respecto, la contribución al análisis de las repercusiones de la dimensión ambiental en otras políticas en sucesivos Programas Comunitarios en materia de medio ambiente y desarrollo sostenible. Asimismo, la Organización para la Cooperación y el Desarrollo Económico (OCDE), a partir del acuerdo adoptado en la reunión Ministerial de 1998, ha aprobado también una estrategia concebida con el doble propósito de uproporcionar orientaciones claras para políticas ambientalmente sostenibles a los Estados y guiar el futuro trabajo de la OCDE en materia ambiental». A diferencia de las estrategias establecidas en el marco de la UE, se plantea con un objetivo pragmático y a corto plazo, 2010, con carácter revisable mediante la elaboración de un programa de indicadores previsto para su seguimiento (OCDE 2002).

En definitiva, se ha marcado el comienzo de nuevos enfoques y, por tanto de análisis, valoraciones y evaluaciones diferentes. Como es notorio, los obstáculos para el desarrollo sostenible suelen afectar a varias políticas sectoriales. Si las políticas se determinan sólo unilateral y sectorialmente, sin tener en cuenta sus efectos colaterales para otros ámbitos, es inevitable que se observen serias incongruencias entre políticas. De ahí, la importancia de la mejora de la integración de las políticas sobre la base de una revisión transparente y sistemática de los costes y de los efectos de las diversas opciones, de modo que las distintas políticas se refuercen mutuamente, se adopten soluciones de compromiso basadas en decisiones informadas y que los objetivos sociales y medioambientales se cumplan con el mínimo coste económico. En consecuencia, los soportes básicos descansan inevitablemente en tres pilares fundamentales:

\subsection{La eficiencia económica a partir del análisis de los costes ambientales}

Esta nueva perspectiva provoca que la adaptación de los problemas ambientales ya no se vean solamente como cuestiones locales (existen responsabilidades sobre los ecosistemas mundiales) y dejan de ser, en cualquier caso, una restricción al desarrollo económico. Empiezan a percibirse los beneficios del medio ambiente, al ser entendido como una factor de «desarrollo positivo» y generador de empleo. La «industria ecológica» (equipamientos de control de la contaminación), en volumen es equivalente a la industria aeronáutica mundial, con una facturación cercana al 2 por 100 del PIB mundial.

El reciente reconocimiento de que el medio ambiente proporciona bienes y servicios -los cuales no entran en las contabilidades nacionales- con tanto o más valor que los que proporcionan los mercados, es un cambio significativo. En este sentido, la aportación realizada por Constanza sobre el valor económico de los servicios proporcionados por los sistemas ecológicos se ha erigido en una referencia valiosa como base para desarrollar enfoques diferentes a los convencionales y de mayor ambición en su campo de análisis (Constanza et al. 1997). Lo más destacable, no obstante, no reside en el valor asignado a los grandes ecosistemas mundiales y al capital

${ }^{5} \operatorname{COM}(2001) 264$. 
natural, sino en la confirmación de que los servicios asociados a la naturaleza dejan de considerarse «dones gratuitos» y el reconocimiento de que su valor fuera de mercado (en su mayor parte) supera ampliamente el valor del Producto Nacional Bruto a escala mundial.

La degradación del capital natural se convierte a largo plazo en pérdidas económicas tangibles. Si los sistemas ecológicos -en la más ortodoxa teoría neoclásica ambiental- no se integran en el sistema de mercado («internalización de la ecología en la economía») se están provocando situaciones de grave ineficiencia. Las «externalidades» ambientales derivadas de las deficiencias del mercado y de los fallos de intervención pública, como responsables de la ineficiente asignación de recursos naturales, a las que habría que añadir los fallos de integración de la dimensión ambiental en las políticas económicas, arrastran efectos multiplicadores en materia de costes. Cuando las disfuncionalidades ambientales se observan preferentemente desde la perspectiva de costes y la pérdida de eficiencia económica, también se puede comprender que la amenaza del subdesarrollo supone graves ineficiencias y una situación de desequilibrio que no beneficia a la estabilidad económica general. Por consiguiente, la eficiencia se erige en un soporte clave (aunque no exclusivo) del desarrollo sostenible.

\section{2. «Sostenibilidad» $\mathrm{y}$ «Sostenibilidad integral»}

La integración entre medio ambiente y desarrollo se debe relacionar con el concepto de sostenibilidad o sustentabilidad. A partir de una perspectiva más amplia e integradora, nos encontramos con el denominado «desarrollo sostenible»; esto es así, al asumir la acepción primaria de sostenibilidad en función de las tareas y prácticas agrobiológicas, puesto que en este ámbito se relaciona el concepto con la capacidad de un sistema para mantener su productividad frente a las perturbaciones. En la «óptica conservacionista», se asume la sostenibilidad en relación unidimensional con criterios fundamentalmente ecológicos. Desde otra perspectiva, más amplia y en fase avanzada, el concepto rebasa la monocorde implicación estrictamente ecológica e incorpora la «dimensión ambiental» para asumir gradual y progresivamente criterios económicos, sociales y culturales.

Frecuentemente, la noción de sostenibilidad suele ser objeto de una utilización limitada y equívoca. Así, al tratar de la «sostenibilidad económica» se suelen omitir los principios básicos de tipo ecológico-ambiental. Es más, se expresan y aplican ideas contradictorias al recurrir al concepto de «desarrollo sostenido», ya que con este término se pretende mantener un progreso económico continuado sin explicitar que lo que tiene que ser sostenible en primer lugar es la base de los recursos del proceso de desarrollo.

Conviene resaltar, como subraya acertadamente Jiménez Herrero, que «sostenibilidad» no puede considerarse como sinónimo de «desarrollo sostenible». Este último concepto incluye objetivos sociales, según determinadas escalas de valores humanos y de necesidades que van cambiando en el tiempo (Jiménez Herrero 1999).

La «sostenibilidad integral» se erige en la premisa básica del «desarrollo sostenible global». Pero no lo es todo. Podríamos pensar en procesos de sostenibilidad de la producción, de los recursos naturales empleados y del capital natural, sin que necesariamente las condiciones y calidad de vida del presente y del futuro fueran las más deseables en términos de bienestar para la totalidad o parte de la población humana. El abuso y la inadecuada utilización de las nociones de sostenibilidad, aplicadas al desarrollo, han propiciado que se presuponga que aquello que es racionalmente deseable también es posible y, más aún, que todo lo que es posible sea en sí mismo deseable. Por tanto, la «sostenibilidad», no puede convertirse en un fundamentalismo cerrado e impermeable, sino en un principio que permite conseguir el fin último de lo que realmente se quiere hacer sostenible. Si la finalidad se canaliza a conseguir un desarrollo humano global y perdurable en el tiempo, éste tendrá que ser ecológica y 
ambientalmente sostenible. Dicho de otra manera: potenciando y protegiendo la diversidad biológica y renovando la base de los recursos naturales sobre los que se apoyen los procesos de desarrollo.

También conviene subrayar la complejidad de la cuestión al intercalar las perspectivas económicas y sociales. La sostenibilidad ecológica-ambiental del sistema global es una condición necesaria, pero no suficiente para lograr el desarrollo sostenible del limitado sistema antrópico. Por lo que, de acuerdo con las actuales corrientes tratadistas de esta problemática, resulta imprescindible profundizar y, en cualquier caso, aclarar el modelo de sostenibilidad de carácter económico y social que deberá complementarse coherentemente con la otra sostenibilidad, esto es, la ecológica y medioambiental.

\subsection{La perspectiva transversal}

Por lo expuesto, se desprende que la noción de sostenibilidad y su aplicación al desarrollo humano, sintetizado en el concepto de «desarrollo sostenible», aparece como un conjunto de relaciones entre sistemas (naturales y sociales), una clara dinámica de procesos (energía, materia e información) y con referencia en escalas de valores. Puesto que los sistemas económicos, ecológicos y sociales se interaccionan entre sí de forma interdependiente, su estabilidad depende de la capacidad para resistir fluctuaciones, mantener la integridad del conjunto y garantizar sus funciones básicas. Como se ha subrayado hasta aquí, la sostenibilidad se debe identificar a partir de la conjunción de varias dimensiones y términos de sistemas (ecológico, económico y social) con sus correspondientes procesos, relacionados con las prioridades y preferencias emanadas de una escala de valores concreta.

Este enfoque tridimensional, implica la elección en un mismo plano de proyecciones cruzadas; de tal manera que la aplicación de indicadores para cada uno de los tres componentes no permite una canalización unidimensional y autónoma y, a la vez, contradictoria con las referencias procedentes de los demás. Así, por ejemplo, cuando se asume el crecimiento económico, dentro de los indicadores convencionales que se identifican con la elección económica, este objetivo -en coherencia con lo anteriormente expuesto- debería asociarse, indisolublemente, con la vertiente social -en este caso, con la distribución de la renta- y, en consecuencia, incorporando las medidas e instrumentos propios para el logro de la correspondiente redistribución (tanto personal como regional) ; además y paralelamente, la racionalidad en la protección y defensa del entorno exige la consideración de los impactos y repercusiones en el patrimonio natural y de los efectos en la alteración y renovación del capital vinculado a los recursos naturales utilizados para obtener el crecimiento del Producto Interior Bruto.

Se trata, por consiguiente, de interacciones que requieren enfoques transectoriales, transdisciplinarios y transversales (Sierra Ludwig 2002: 17-21).

No obstante, tampoco hay que subvalorar las elevadas limitaciones existentes en la actualidad para el conocimiento de la compleja realidad asociada al medio ambiente. Salvo en los supuestos de programaciones concretas que cuentan con la fijación clara de objetivos, de instrumentos aplicables y de mecanismos de ejecución y con la obtención de realizaciones identificables en el conjunto del proceso, en los demás casos, a la complejidad mencionada, se adosan insuficiencias de datos de base que dificultan el análisis evaluatorio en todos los eslabones. Por consiguiente, hay que resaltar la falta de solidez de muchos soportes básicos para la evaluación en estas materias.

La interacción de esfuerzos carecerá de consistencia si -desde la plataforma analítica, a partir de la formación y de la sensibilización científica- no se insiste sobre un hecho determinante: la importancia de la disponibilidad y de la calidad de los datos. La falta de referencias sólidas y de estadísticas completas, fiables y adoptables se erige en un obstáculo demasiado persistente para la investigación y en un freno para la toma de decisiones fundamenta- 
das. Estas deficiencias proceden de dos elementos muy relacionados y también de distinta peculiaridad etiológica: por un lado, el desarrollo de la investigación y del campo analítico en ese sentido resulta demasiado incipiente y desigual entre países y regiones; y, por otra parte, muchos efectos surgen con claros desfases temporales y espaciales en su aparición respecto a la irrupción de la causa desencadenante que imprimen un «carácter difuso» al fenómeno analizable.

En los aspectos «cualitativos» las dificultades se disparan; si bien, en muchas ocasiones, el discurrir de las tendencias se suele diagnosticar a partir de la constatación de datos cualitativos. Las recientes recopilaciones sistemáticas -como el soporte del Informe Dobris, en Europa, los Indicadores del Desarrollo del Banco Mundial o los Indicadores de Desarrollo Sostenible, basados en la metodología auspiciada por las Naciones Unidas- constituyen un paso importante para poder, al menos, fijar los cimientos que permitan diseñar políticas coherentes a partir de las contrastaciones basadas en la experiencia y en los resultados alcanzados. Se trata de partir de una plataforma común y razonablemente asumible. A pesar de la indudable ventaja comparativa que al respecto goza el marco de los países miembros de la Unión Europea, parece conveniente volver a recordar la necesidad de superar las lagunas actuales que impiden contar, en demasiadas ocasiones, con datos consistentes, amplios, homogéneos y revisados sistemática y periódicamente.

\section{REFERENCIAS BIBLIOGRÁFICAS Y DOCUMENTALES}

Agencia Europea de Medio Ambiente (2000), Annual European Community Greenhouse Gas Inventory. Informe Técnico número 19. Copenhague: AEMA.

- (2004), Analysis of Greenhouse Gas Emission trends and proyections in Europe 2.004. Copenhague: AEMA.

- (2005), Annual European Community Greenhouse Gas Inventory 1990-2003 and Inventory Report 2005. EE A Informe Técnico número 4. Copenague: AEMA.

Blok, K. et al. (2001), Economic Evaluation of detectorial Emission Reduction Objectives for Climate Change. ECOFYS Energy and Environment, AEA Technology Environment y Universidad Técnica Nacional de Atenas.

Capros, P. y Mantzos, L. (2000), The Economic Effects of EU-wide Industry-Level Emission Trading to Reduce Greenhouse GasesResults from PRIMES model. Atenas: Instituto de Comunicación y Universidad Técnica Nacional de Atenas.

Cline, W. R. (1992), The Economic of Global Warming. Washington: Institute for International Economics.

Comisión de las Comunidades Europeas (2000), Grünbuch zum Handel mit Treibhausgasemissionen in der Europaeischen Union. Bruselas: Comisión de las Comunidades Europeas.

- (2001), Comunicación de la Comisión acerca de la ejecución de la primera fase del Programa Europeo sobre el Cambio Climático. Bruselas: Comisión de las Comunidades Europeas.

Comisión Europea (2005), EU Emissions Trading. Bruselas: Comisión Europea.

Costanza, R. et al. (1997), «The Value of the World’s Ecosystem Services and Natural Capital», Nature 253 (387).

D. G. Joint Research Centre (2000), Preliminary Analysis of the Implementation of an EU-wide Permit System on $\mathrm{CO}_{2}$ Emissions Abatement Costs-Results from POLES model. Sevilla: Instituto de Estudios de Prospectiva Tecnológica.

Fankhauser, S. (1995), Valuing Climate Change. The economics of the Greenhouse. Londres: Earthscan.

Harmelink, M. et al. (2001), Kyoto without the US: Cost and Benefits of EY Ratification of the Kyoto Protocol. Holanda: ECORYS.

Hendriks, C. et al. (2001), Bottom-up Análisis of Emision Reduction. Potentials and Cost for Greenhouse Gases in the EU. Utrecht: ECOFYS y EA Technology. 
IPCC (2000), Emission Scenarios. Special Report of the IPCC. Cambridge: Cambridge University Press.

- (2001a), Climate Change 2001: Mitigation: Summary for Policymakers and Technical Summary of the Working Group III Report. Cambridge: Cambridge University Press.

- (2001b), Climate Change 2001: Impacts, Adaptation and Vulnerability. Cambridge: Cambridge University Press.

- (2001c), Climate Change 2001: Synthesis Report. Ginebra: IPCC.

Jiménez Herrero, L. M. (1999), «Cambio global, desarrollo sostenible y coevolución», en Jiménez Herrero, L.M. e Higón Tanavit, F. J., eds., Ecología y economía para un desarrollo sostenible. Valencia: Universidad de Valencia.

Ministerio de Medio Ambiente (2000), Estrategia Española sobre Cambio Climático para el cumplimiento del Protocolo de Kyoto. Madrid: Ministerio de Medio Ambiente.

Nordhaus, J. (1991), «Economic Approaches to Greenhouse Warming», en VV.AA. Global Warming: Economic Policy Responses. Cambridge MA: MIT Press.

Ocaña Pérez de Tudela, C. (2003), El impacto del Protocolo de Kyoto sobre la economía española. Zaragoza: Universidad de Zaragoza, Fundación SAMCA y Fundación BBVA.

OCDE (2001), Les taxes liées à l'enwironnement dans les pays de l'OCDE. Problèmes et stratègies. Paris: OCDE.

- (2002), OCDE Environmental Strategy for the First Decade of the 21st Century. Paris OCDE.

Oxford Economic Forecasting (2002), Macroeconomic analysis of EU-wide emissions trading. Oxford: OEF.

Pacala, S. y Socolow, R. (2004), «Stabilization Wedges: Solving the Climate Problem for the Next 50 Years with Current Technologies», Science 305.

PricewaterhouseCoopers (2004), Efectos de la aplicación del Protocolo de Kyoto en la economía española. Madrid: PricewaterhouseCoopers.

Philip, L. (2004), «نCuánto cuesta Kyoto?», Ambienta 34: 26-33; MIMAM.

Sierra Ludwig, V. (1996a), «Interacciones econo-climáticas en el contexto de la constatación empírica disponible», RAE 5: 151-192. Oviedo: Universidad de Oviedo.

- (1996b), «La utilización de instrumentos fiscales y de mercado en la política ambiental», Boletín de Información Comercial Española 2.484.

- (2001), «El proceso de adaptación económica ante el reto de la protección ambiental», Cuadernos de Información Económica 162.

- (2002), «Desarrollo sostenible: acotaciones conceptuales y revisiones estratégicas», Boletín de Información Comercial Española 2.749.

- (2004a), «Cambio Climático, Efecto Invernadero, Protocolo de Kyoto y algunas reflexiones», Cuadernos de Información Económica 185.

- (2004b), «Protocolo de Kyoto: compromisos incumplidos e instrumentos emergentes», Boletín de Información Comercial Española 2.815.

- (2005), «Cambio Climático, Efecto Invernadero, Protocolo de Kyoto y algunas reflexiones», Cuadernos de Información Económica 185.

Sierra Ludwig, V. y Weidner, L. (2005), «Wichtige Grundlagen für den Schutz. Neue Perspektiven», Nene Hefte 1.

Zapico Goñi E.y Mayne, J. (2000), Seguimiento de los resultados de la gestión en el Sector Público. Perspectivas desde la experiencia internacional. Madrid: Instituto de Estudios Fiscales. 